\title{
Epigenetic Regulation of Mammalian Target of Rapamycin Debilitates Insulin Resistance Associated Alzheimer Disease Condition in Rats
}

Violina Kakoty ( $\sim$ pompykakoty666@gmail.com)

Birla Institute of Technology and Science Pilani: Birla Institute of Technology and Science https://orcid.org/0000-0001-8366-8142

\section{Sarathlal KC}

Birla Institute of Technology and Science Pilani: Birla Institute of Technology and Science

Sunil Dubey

Emami Limited

Chih Hao Yang

Taipei Medical University School of Pharmacy: Taipei Medical University College of Pharmacy

\section{Rajeev Taliyan}

Birla Institute of Technology and Science Pilani: Birla Institute of Technology and Science https://orcid.org/0000-0003-2147-2990

\section{Research Article}

Keywords: Alzheimer disease, High fat diet, Autophagy, Histone deacetylase inhibitor, Rapamycin, Vorinostat

Posted Date: May 14th, 2021

DOl: https://doi.org/10.21203/rs.3.rs-472911/v1

License: (c) (1) This work is licensed under a Creative Commons Attribution 4.0 International License. Read Full License 


\section{Abstract}

Insulin resistance (IR) and accumulation of amyloid beta $(A \beta)$ oligomers are potential causative factor for Alzheimer Disease (AD). Simultaneously, enhanced clearance level of these oligomers through autophagy activation bring novel insights into their therapeutic paradigm. Autophagy activation is negatively correlated with mammalian target of rapamycin (mTOR) and dysregulated mTOR level due to epigenetic alterations can further culminate towards $A D$ pathogenesis. Therefore, in the current study we explored the neuroprotective efficacy of rapamycin and vorinostat in-vitro and in-vivo. A $\beta_{1-42}$ treated SH-SY5Y cells were exposed to rapamycin $(20 \mu \mathrm{M})$ and vorinostat $(4 \mu \mathrm{M})$ to analyse mRNA expression of amyloid precursor protein (APP), brain derived neurotrophic factor (BDNF), glial cell derived neurotrophic factor (GDNF), neuronal growth factor (NGF), beclin-1, microtubule-associated protein 1A/1B-light chain 3phosphatidylethanolamine conjugate, lysosome-associated membrane protein 2 and microtubule associated protein 2. In order to develop IR condition, rats were fed a high fat diet (HFD) for 8weeks and then subjected to intracerebroventricular $A \beta_{1-42}$ administration. Subsequently, their treatment was initiated with rapa ( $1 \mathrm{mg} / \mathrm{kg}$, i.p.) and vori $(50 \mathrm{mg} / \mathrm{kg}$, i.p.) once daily for 28 days. Morris water maze was performed to govern cognitive impairment followed by sacrification for subsequent biochemical and histological estimations. For all the measured parameters, a significant improvement was observed amongst the combination treatment group in contrast to that of the HFD $+A \beta_{1-42}$ group and that of the groups treated with the drugs alone. Outcomes of the present study thus suggest that combination therapy with rapa and vori provide a prospective therapeutic approach to ameliorate AD symptoms exacerbated by IR.

\section{Introduction}

Given the fact that the brain is an insulin-sensitive organ, numerous mechanism(s) converge towards the possibility that insulin resistance (IR) condition is one of the major factor for aggravating Alzheimer disease (AD)(Boles et al., 2017), although the exact known mechanism is far from being established. The presence of insulin can be seen in various parts of the brain, including hippocampus where AD patients are mostly affected. Insulin also plays vital roles in the brain like maintenance of synaptic plasticity(Ferreira et al., 2018), regulation of pro-inflammatory cytokine secretion in microglia and astrocytes in-vitro etc (J Spielman et al., 2015; Labandeira-Garcia et al., 2017). However, given allied functional roles played by insulin in the brain, the exact pathological mechanism(s) that leads to aggravation of $A D$ due to IR remains enigmatic.

$A D$ is a progressive memory related neurodegenerative disorder evoking devastating cognitive impairments in affected individuals. Symptoms usually start with forgetting names/dates of important persons or events that eventually lead up to a complete loss of memory(Jahn, 2013). In many cases, the predominant pathological hallmark of $A D$ typically embodies misfolding of amyloid beta $(A \beta)$ and hyperphosphorylation of tau paving way for formation of neurofibrillary tangles (NFTs)(M Ashraf et al., 2014), although in some cases the cause can also be genetic. 
In addition to the classical pathological hallmark of $A D$, epidemiological studies also suggest a direct correlation between IR and AD mainly through the formation of $A \beta$ oligomers(Mullins et al., 2017). A recently performed preclinical study in our lab further confirmed this hypothesis where nanoformulated form of rosiglitazone, a well-known drug for treatment of type 2 diabetes mellitus (T2DM) was used for the treatment of IR complicated streptozotocin (STZ) induced AD in mice(Sarathlal et al., 2020). Such kind of metabolic complication induced $A D$ are further associated with typical epigenetic modifications that might deleteriously affect the disease condition, majorly being histone modifications. In continuation to the above study we have also examined the beneficiary effect of rosiglitazone in combination with a potent histone deacetylase inhibitor (HDACi), vorinostat (vori) in exerting neuroprotection against IR induced $A D$ in mice( $K$ C et al., 2021).

We have already explored the therapeutic efficacy of anti-diabetic drugs and HDACis alone and in combination in decreasing the IR associated AD pathology, however, recently our interest extended towards autophagy, a mechanism responsible for flushing away misfolded proteins to maintain homeostasis in the body. It is believed that during neurodegeneration autophagy has a crucial role to play, however its combination with epigenetics to unravel their therapeutic efficacy during IR associated AD is not yet explored. In this regard, we selected a highly potent autophagy activator, rapamycin (rapa) and vori to explore its potential in the aforementioned disease pathogenesis.

In $A D$, increase in the aggregated/mutant forms of $A \beta$ renders failure in the process of autophagy resulting in a toxic build-up and neuronal degeneration over time. Recent studies have confirmed the role of rapa as an autophagy inducer and promotor of delayed aging extending lifespan in mice neurodegenerative models(Selman et al., 2009). Rapa mainly orchestrates its signalling through target of rapa (TOR) pathway divided into two complexes, mTORC1 and mTORC2(Guertin et al., 2006) that senses nutrient/growth factor availability with cell metabolism(Sarbassov et al., 2005). mTORC1 inhibits autophagy through Unc51-like kinase 1 (ULK1) phosphorylation and mAtg13, the mammalian homologs of the yeast kinase Atg1 and Atg13 respectively, which are essential for the formation of preautophagosomal structures(Mizushima, 2010) in response to the presence of abundant nutrients and energy. On the other hand, mTORC2 also regulates autophagy through mTOR, phosphorylating and activating Akt and PKC(Zeng et al., 2007). Positive modulation of mTORC1 by Akt through its phosphorylation by mTORC2 activates mTORC1 function, thereby inhibiting autophagy. Long term treatment with rapa in transgenic mouse models (hAPP (J20) or PDAPP) have prevented AD-like cognitive deficits with decreased levels of $A \beta_{42}$ (Spilman et al., 2010). The results of the study confirmed that inhibition of mammalian target of rapa (mTOR) activated autophagy in the hippocampus of rapa treated mice, however, similar result was not being observed in non-transgenic PDAPP mice delineating the fact that $A \beta$ reduction with cognitive ability improvement may be due to increased neuronal autophagy as a result of response to high $A \beta$ levels in transgenic mice.

Further, in a study conducted by Madeo, Kroemer, and coworkers, it was established for the first time that autophagy induction could suffice upon histone posttranslational modifications where the cytoprotective autophagy activation in aging yeast was confirmed upon treatment with spermidine majorly due to 
inhibition of histone acetylation, particularly, lki3 and Sas3, causing global histone $\mathrm{H} 3$ hypoacetylation, thereby repressing gene expression. Additionally, acetylation of histone H4 lysine 16 (H4K16ac) is reduced upon autophagy induction by numerous stimuli. Decreased levels of autophagy-related genes, such as, ATG9A, GABARAPL2, MAP1LC3, ULK1, ULK3, and VMP1 is correlated with H4K16 deacetylation(Füllgrabe et al., 2013). Experimental evidence strongly suggests that inhibition of the autophagic H4K16 deacetylation does not necessarily inhibit autophagy but indeed increases autophagic flux which is consistent with genome-wide investigations. Similarly, histone methylation, particularly, di and trimethylation of histone $\mathrm{H} 3$ at lysine 4(Wend et al., 2013) and H4K20(Schotta et al., 2004) are critically associated with controlling the expression of major autophagy related proteins/genes modulating transcriptional activation and repression. Previous results from our lab have already demonstrated that Sodium Butyrate (SB), a pan HDACi can elicit major neuroprotective potency against 6-hydroxydopamine induced PD in rats owing to its rigorous histone acetylation action and great blood brain barrier permeability(Sharma, Taliyan, \& Singh, 2015). Moreover, several models of AD evidenced lower histone acetylation levels(Marques \& Outeiro, 2013), for instance, vori in combination with curcumin elicits synergistic neuroprotective efficacy in A $\beta$ toxicity induced in PC12 cells(Meng et al., 2014).

Hence, in the current study, initially, SH-SY5Y cells were used to determine the neuroprotective potential of a potent combination of rapa and vori. High fat diet (HFD) fed animals were induced with $A \beta_{1-42}$ peptide to mimic IR induced $A D$ condition in wistar rats. Post induction of $A D$, rats were administered with rapa and vori for a period of 28days. Both the drugs were administered alone as well as in combination to investigate the possible effects on the behavioural outcome, mRNA expression of relevant marker proteins, biochemical estimation of growth factors and pyknotic neuronal count.

\section{Material And Methods}

Drugs and chemicals: $A \beta_{1-42}$ peptide (Sigma-Aldrich), Rapamycin (Sigma-Aldrich), Vorinostat (Cayman chemical), Dulbecco's Modified Eagle's Medium/ Ham's F-12 (DMEM/F12), Trypsin (Sigma-Aldrich), Glucose solution (Gibco), fetal bovine serum (FBS) (Genetix and Himedia), 3-(4, 5dimethythiazol-2-yl) 2, 5diphenyl tetrazolium bromide (MTT) powder, cell culture grade antibiotic (Genetix), haematoxylin and eosin were acquired from Sigma-Aldrich, USA; TRIzol ${ }^{\mathrm{TM}}$ Reagent from Invitrogen, USA, RevertAid Reverse Transcriptase, Random hexamer and 2x Maxima SYBR Green/ROX qPCR Master Mix were acquired from Thermo Fischer, USA; $A \beta_{1-42}$, ptau, brain derived neurotrophic factor (BDNF), glial cell derived neurotrophic factor (GDNF) and neuronal growth factor (NGF) ELISA kit were procured from Boster Biotech, USA. Colorimetric kits for total cholesterol (TC), triglycerides (TG) and low density lipoprotein (LDL) were purchased from coral clinical systems, India; and global histone $\mathrm{H} 3$ acetylation kit was purchased from epigentek. Primers: BDNF, GDNF, NGF, amyloid precursor protein (APP), beclin-1, microtubule-associated protein 1A/1B-light chain 3-phosphatidylethanolamine conjugate (LC3), lysosome-associated membrane protein 2 (LAMP-2), microtubule associated protein-2 (MAP-2) and glyceraldehyde 3-phosphate dehydrogenase (GAPDH) were procured from Imperial life sciences limited. 
Other reagents of analytical grade were obtained from CDH and SRL, India, and all the biological solvents for the study were freshly prepared just before use.

In-vitro experimental procedures

\section{Cell culture}

SH-SY5Y cell lines were obtained from National Centre for Cell Science, Pune, India and were maintained in DMEM/F12 and 10\% FBS supplemented with $0.584 \mathrm{~g} / \mathrm{L}$ of glutamine and $1000 \mu \mathrm{l} / \mathrm{L}$ of antibiotics (penicillin-streptomycin). After the cells were $70 \%$ confluent they were sub-cultured and maintained in an incubator with $5 \% \mathrm{CO}_{2}$ at $37^{\circ} \mathrm{C}$.

\section{MTT assay}

Briefly, confluent cells were trypsinized and transferred to a $2 \mathrm{ml}$ media containing $15 \mathrm{ml}$ centrifuge tube which was then centrifuged at 2000 rpm for $5 \mathrm{~min}$ in $24^{\circ} \mathrm{C}$ (Eppendorf, $5430 \mathrm{R}$ ). After centrifugation the supernatant was discarded and the formed pellet was re-suspended in $1 \mathrm{ml}$ media. $10^{4} \mathrm{cell} / \mathrm{s} / \mathrm{ml}$ was diluted and into each well of 96 well plate was added $200 \mu$ l of cell suspension. A culture condition of $37^{\circ} \mathrm{C}$ and $5 \% \mathrm{CO}_{2}$ was maintained for incubation of the 96 well plate. To evaluate the percentage growth inhibition at 12, 24 and 36h, three 96 well plates were prepared. Further, rapa at a concentration of 0,5, 10,20 and $40 \mu \mathrm{M}$ and vori at a concentration of $0,1,2,4,8 \mu \mathrm{M}$ was added separately as well as in combination, after the cells were adhered to the culture plate. Cells were washed with $1 \mathrm{X}$ phosphate buffered saline (PBS) and $200 \mu \mathrm{l}$ of MTT $(0.5 \mathrm{mg} / \mathrm{ml})$ was added and incubated for 3 hours. MTT was

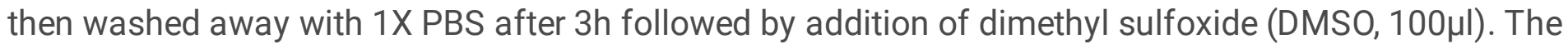
mixture was then kept at room temperature for $15 \mathrm{~min}$ until the cells were lysed and forms a violet colour. The optical density (OD) was recorded at $573 \mathrm{~nm}$ with $670 \mathrm{~nm}$ as reference wavelength. The formula used for calculating the percentage growth inhibition of cells treated with rapa and vori was: $\%$ Inhibition $=100$ - (Test OD/Non-treated OD)*100. Each sample was analysed in triplicate.

\section{Drug treatment}

For treatment of the respective drugs, SH-SY5Y cells were seeded at a concentration of $2.5 \times 10^{4}$ cells/ well in a 6 well plate provided with DMEM/F12 supplemented with $10 \% \mathrm{FBS}$ and maintained at $37^{\circ} \mathrm{C}$ with $5 \% \mathrm{CO}_{2}$. After gaining $50-60 \%$ confluency, the cells were treated with $25 \mathrm{mM}$ of glucose except for control(Khan et al., 2019; Yang et al., 2013). Further, 4 wells were exposed to $10 \mu \mathrm{M}$ of $A \beta_{1-42}$ alone (Ozansoy et al., 2020) as well as in the presence of $20 \mu \mathrm{M}$ rapa, $4 \mu \mathrm{M}$ vori and their combination for $24 \mathrm{~h}$ (rapa, $10 \mu \mathrm{M}$ and vori, $2 \mu \mathrm{M}$ ) (Table 1). 
Table 1

Division of in-vitro experimental groups and their respective treatment.

\begin{tabular}{|c|c|c|}
\hline S. & Group & Treatment \\
\hline 1 & Control & Cells cultured without exposure to any treatment \\
\hline 2 & High Glucose (Hi. Glu.) & Cells cultured with $50 \mathrm{mM}$ of high glucose \\
\hline 3 & Hi. Glu. $+A \beta_{1-42}$ & $\begin{array}{l}\text { Cells cultured with } 25 \mathrm{mM} \text { of high glucose and } 10 \mu \mathrm{M} \text { of } \\
\mathrm{A} \beta_{1-42}\end{array}$ \\
\hline 4 & Hi. Glu.+ $A \beta_{1-42}+$ rapa $(20 \mu M)$ & $\begin{array}{l}\text { Cells cultured with } 25 \mathrm{mM} \text { of high glucose, } 10 \mu \mathrm{M} \text { of } A \beta_{1-42} \\
\text { and rapa } 20 \mu \mathrm{M}\end{array}$ \\
\hline 5 & Hi. Glu. $+A \beta_{1-42}+$ vori $(4 \mu M)$ & $\begin{array}{l}\text { Cells cultured with } 25 \mathrm{mM} \text { of high glucose, } 10 \mu \mathrm{M} \text { of } A \beta_{1-42} \\
\text { and vori } 4 \mu \mathrm{M}\end{array}$ \\
\hline 6 & $\begin{array}{l}\text { Hi. Glu. }+A \beta_{1-42}+\text { rapa }+ \text { vori }(10 \\
\text { and } 2 \mu \mathrm{M} \text { resp. })\end{array}$ & $\begin{array}{l}\text { Cells cultured with } 25 \mathrm{mM} \text { of high glucose, } 10 \mu \mathrm{M} \text { of } A \beta_{1-42} \\
\text { and rapa } 10 \mu \mathrm{M} \text { vori } 2 \mu \mathrm{M}\end{array}$ \\
\hline
\end{tabular}

\section{Ribonucleic acid (RNA) isolation and cDNA synthesis}

The total RNA was isolated from the cell lysate using TRIzol ${ }^{\text {TM }}$ Reagent (Invitrogen ${ }^{\text {TM }}$, 15596018) according to manufacturer's protocol. Complementary deoxyribonucleic acid (cDNA) was further synthesized using RevertAid Reverse Transcriptase (Thermo Fisher, EP0441) and Random hexamer (Thermo Fisher, S0142). Real-time quantitative polymerase chain reaction (qRT-PCR)

The qRT-PCR assays were performed using the CFX Connect Optics Module (Bio-Rad). For amplification 2X Maxima SYBR Green/ROX qRT-PCR Master Mix (Thermo Fisher, K0221) was used according to manufacturer's instructions with specific primers (Table 2). PCR conditions were $95^{\circ} \mathrm{C}$ for $10 \mathrm{~min}$ followed by 40 cycles of $95^{\circ} \mathrm{C}$ for $15 \mathrm{~s}, 60^{\circ} \mathrm{C}$ for $30 \mathrm{~s}$ and $72^{\circ} \mathrm{C}$ for $30 \mathrm{~s}$. The relative expression levels of various mRNA were calculated using the $2^{-\triangle \Delta C T}$ method(Sarathlal et al., 2020). Each sample was analysed in triplicate. 
Table 2

List of primer sequences used for in-vitro experiments.

\begin{tabular}{|lll|}
\hline Gene & Forward Primer & Reverse Primer \\
\hline APP & AGCCTCTGAAGTTGGACAGC & AGAAGCAGCTGAACTCCCAC \\
\hline GDNF & GGCATCACCTACACACCACA & GGAGTTGATAGGCAAGGCCA \\
\hline NGF & ATAAGCTTCCCAATCAGCTCTCG & GGTTTGCTTGCACTCAGCTC \\
\hline BDNF & GGAACTGAAAGGGTCTGCGA & TCCCCAGAGACTAACCCGAG \\
\hline Beclin-1 & TGCTTGCAGTACTGGGTCAG & TGAGAAAGGCGAGACACGTT \\
\hline LC3 & TTCCGAGTTGCTGACTGACC & CCCTTGTAGCGCTCGATGAT \\
\hline LAMP2 & CATGTACCACCCTCCTACGC & CCCCTAGTCTTATGACTCGCAC \\
\hline MAP2 & GCACACTCACATCCACCTGA & TGTGAGGGGTCCTGGGATAG \\
\hline GAPDH & GCAACTAGGATGGTGTGGCT & TCCCATTCCCCAGCTCTCATA \\
\hline
\end{tabular}

In-vivo experimental procedures

\section{Animals}

All the experimental animals (Wistar rats; male; 8-10 weeks; weighing around 200-250gram) were housed at central animal facility, BITS-Pilani, Pilani campus with standard laboratory conditions (temperature: $20-22^{\circ} \mathrm{C}$, humidity: $65 \%$ ) on a $12: 12$ hour light:dark cycle with freely available food and water. All experiments and sample collection were performed in compliance with the approval of Institutional Animal Ethics Committee (IAEC) -BITS-Pilani, Pilani Campus, Rajasthan (Approved protocol No: IAEC/RES/24/14/Rev-1/28/34).

\section{Induction of insulin resistance}

Animals were fed with a HFD for a period of 8weeks and the HFD composition was similar to as described by Srinivasan et al(Srinivasan et al., 2005). The mice subjected to HFD exhibited characteristic features of IR as confirmed after assessment of serum TC, TG and LDL using commercially available colorimetric tests.

\section{Induction of Alzheimer disease by $A \beta_{1-42}$}

IR induced Alzheimer type of dementia animal model was developed by feeding mice with HFD for 8 weeks, followed by injecting freshly prepared $A \beta_{1-42}$ peptide solution as discussed previously(Krishna et al., 2020) at a nominal dose of $5 \mu \mathrm{M} / \mathrm{kg}$ into the lateral cerebral ventricles using the previously reported coordinates(Sharma \& Taliyan, 2015). Briefly, midline sagittal incision was made over the scalp to open the rat skull by placing the rat head in the exact location of the stereotaxic apparatus (Inco Ambala, India). Prior to the stereotaxic surgery, rats were anesthetized using an intraperitoneal injection of ketamine-xylazine mixture $(80 \mathrm{mg} / \mathrm{kg}$ and $5 \mathrm{mg} / \mathrm{kg}$, respectively). Antiseptic powder (Neosporin) and a 
single dose of intraperitoneal injection of gentamicin $(40 \mathrm{mg} / \mathrm{kg})$ were administered after surgery to prevent sepsis.

\section{Experimental protocol}

Briefly, animals were divided into 6 groups and each group comprised of 6 animals as described in Table 3. The treatment was continued for 28 days. The drugs (rapa and vori) were prepared freshly just before use every day. Dose for vori was selected based on study conducted previously in our lab(K C et al., 2021; Sharma \& Taliyan, 2016) whereas dose for rapa for neuroprotection was selected based on available literature(Lu et al., 2015). Rapa was initially dissolved in $100 \%$ ethanol, stored at $20^{\circ} \mathrm{C}$, and diluted immediately before use in a vehicle solution containing 5\% Tween 80, 5\% PEG 400, and 4\% ethanol. Rats were injected i.p. once daily for 28 days. Vori was prepared by dissolving in $12.5 \% \mathrm{v} / \mathrm{v}$ DMSO in saline and injected i.p once daily for 28 days. The behavioural parameters were assessed during the last week. Afterwards the animals were sacrificed and various biochemical parameters, mRNA analysis and histological assessments were performed. The experimental regimen and treatment groups are described in Fig. 1 and Table 3 respectively.

Table 3

Division of experimental groups and their respective treatment.

\begin{tabular}{|lll|}
\hline $\begin{array}{l}\text { S. } \\
\text { No. }\end{array}$ & Group & Treatment \\
\hline 1 & $\begin{array}{l}\text { Normal pellet } \\
\text { diet (NPD) }\end{array}$ & Animals were subjected to feeding with NPD. \\
\hline 2 & HFD & $\begin{array}{l}\text { Animals were fed with HFD and infused with buffer into the lateral cerebral } \\
\text { ventricles. }\end{array}$ \\
\hline 3 & HFD $+\mathrm{A} \beta_{1-42}$ & HFD animals were infused with $\mathrm{A} \beta_{1-42}$ into the lateral cerebral ventricles. \\
\hline 4 & Rapa & HFD $+\mathrm{A} \beta_{1-42}$ animals were administered with rapa $1 \mathrm{mg} / \mathrm{kg}$, i.p. \\
\hline 5 & Vori & HFD $+\mathrm{A} \beta_{1-42}$ animals were administered with vori $50 \mathrm{mg} / \mathrm{kg}$, i.p. \\
\hline 6 & Rapa and Vori & $\begin{array}{l}\mathrm{HFD}+\mathrm{A} \beta_{1-42} \text { animals were administered with a combination of rapa } \\
(0.5 \mathrm{mg} / \mathrm{kg}) \text { and vori }(25 \mathrm{mg} / \mathrm{kg}), \text { i.p. }\end{array}$ \\
\hline
\end{tabular}

\section{Behavioural assessment:}

\section{Morris water maze test}

Morris water maze (MWM) test is the most widely used behavioural test to analyse spatial learning and memory. Briefly, the latency to escape towards the submerged platform was recorded. The animal attains a memory for the submerged position of platform using spatial information(Morris, 1984). A circular tank of $120 \mathrm{~cm}$ diameter and $60 \mathrm{~cm}$ height with water filled upto $40 \mathrm{~cm}$ divided into four equal quadrants as south-west (SW), north-west (NW), north-east (NE) and south-east (SE) was used. The platform was kept $2 \mathrm{~cm}$ below the level of water on a randomly chosen quadrant of the pool and the position was kept 
constant throughout the experiment. Initially animals were allowed to swim freely for 60 seconds without platform. For the training session each animal received 4 trials once from each starting point. The ceiling time was kept to 60 seconds. The animals are allowed to remain on the platform for 30 seconds before initiating the next trial. The escape latency (the time taken to locate hidden platform) was recorded using ANY-Maze video tracking system (Stoelting, USA) (Sharma, Taliyan, \& Ramagiri, 2015; Sharma \& Taliyan, 2014).

\section{Probe trial}

The reference memory was assessed using probe trial after 24 hours of MWM trial. In brief, the platform was removed and animals were released from one of the quadrant and allowed to explore the location of platform for 60 seconds. To evaluate the reference memory, the time it spent on target quadrant was recorded using ANY-Maze video tracking system (Stoelting, USA)(Sharma, Taliyan, \& Ramagiri, 2015; Sharma, Taliyan, \& Singh, 2015).

\section{Blood Collection and serum isolation}

Blood was collected using retro-orbital method. Each animal was hand restrained, the neck was gently scuffed and the eye was made to bulge. A glass capillary was inserted. Blood was allowed to flow by capillary action into the $2 \mathrm{ml}$ centrifuge tube. The tubes were then centrifuged at $4000 \mathrm{rpm}, 4^{\circ} \mathrm{C}$ for $20 \mathrm{~min}$ and the serum was separated in another centrifuge tube.

\section{Serum metabolic parameters}

Serum TG, TC and LDL cholesterol levels were measured using commercially available kits as per manufacturer's instructions. Each sample was analysed in triplicate.

\section{Hippocampus homogenate preparation}

Animals were sacrificed by decapitation, brains were removed and rinsed with ice-cold $(0.9 \% \mathrm{w} / \mathrm{v} \mathrm{NaCl})$ isotonic saline. The whole hippocampal region was isolated and the CA1 and DG region was also separated(Chen et al., 2005) which was homogenized with ice cold $0.1 \mathrm{M}$ phosphate buffer ( $\mathrm{pH} 7.4$ ) in a volume 10 times (w/v) the weight of tissue for ELISA estimations and with TRIzol ${ }^{\text {TM }}$ Reagent for mRNA estimation. The homogenate was centrifuged at $12000 \mathrm{~g}$ for $15 \mathrm{~min}\left(4^{\circ} \mathrm{C}\right)$ and aliquots of supernatant were separated(Sharma \& Taliyan, 2015).

\section{Protein determination}

Protein content in brain hippocampus samples was measured by the method of Lowry using BSA (1 $\mathrm{mg} / \mathrm{ml}$ ) as a standard(Classics Lowry et al., 1951). Each sample was analysed in triplicate.

\section{Real-time quantitative polymerase chain reaction (qRT-PCR)}

The total RNA was isolated from hippocampal homogenates and qRT-PCR assay was performed with protocol described under in-vitro experiments. The primers used for in vivo mRNA expression level is 
listed in Table 4.

Table 4

List of primer sequences used for in-vivo experiments.

\begin{tabular}{|lll|}
\hline Gene & Forward Primer & Reverse Primer \\
\hline APP & GAGGTAGTCCGAGTTCCCAC & GCTCGTAGATCACACGGAGG \\
\hline GDNF & GGAGACCGGATCCGAGGTG & TCGGGCATATTGGAGTCACTG \\
\hline NGF & TGGAGCTATCCATCCCGTGT & GTCAATCCTCATCCCAGCCG \\
\hline BDNF & CATAACCCCGCACACTCTGT & TGGCCTTTTGATACCGGGAC \\
\hline Beclin 1 & GAATGGAGGGGTCTAAGGCG & CTTCCTCCTGGCTCTCTCCT \\
\hline LC3 & GGTATCTGGCCGCTTCTTGT & GGTCTCCACAACTTAGGCCC \\
\hline LAMP-2 & ATCCCAGCTTCCATTGGGTG & ATGATGGCGCTTGAGACCAA \\
\hline MAP 2 & GCACACTCACATCCACCTGA & TGTGAGGGGTCCTGGGATAG \\
\hline GAPDH & GCATCTTCTTGTGCAGTGCC & GATGGTGATGGGTTTCCCGT \\
\hline
\end{tabular}

\section{Estimation of global histone $\mathrm{H} 3$ acetylation level}

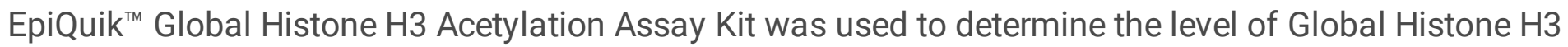
acetylation according to manufacturer's instruction. The protocol consists of nucleic extraction whereby the hippocampus was homogenized using lysis buffer, followed by histone extraction where the histone proteins are extracted using the extraction buffer and then protein content was measured using Lowry's method and lastly histone $\mathrm{H} 3$ acetylation detection where the histone proteins can be stably spotted on the strip wells. A high affinity antibody was used to detect the acetylated histone H3. HRP conjugated secondary antibody-colour development system quantified the amount of acetylated histone H3 and was proportional to the intensity of the developed colour. Each sample was analysed in triplicate.

\section{Histopathological analysis}

The brains were rapidly removed cut into $5 \mu \mathrm{m}$ thick sections, fixed with formalin ( $10 \% \mathrm{v} / \mathrm{v})$ and embedded into paraffin wax followed by standard rehydration steps. Further, the sections were stained with haematoxylin and eosin stain (H \& E) followed by standard dehydration steps (Sharma \& Taliyan, 2014). The slides were coverslipped and hippocampal DG and CA1 region were examined under bright field illumination using Optika TCB5 microscope (Optika Research Microscope, Italy) at 100X and 400X magnifications. Each sample was analysed in triplicate.

\section{Statistical Analysis}

The results were expressed as mean \pm SD. The behavioural and biochemical parameters were analysed by one-way analysis of variance (ANOVA) followed by Tukey's post hoc test using statistical graph pad 
prism software (version 6.01 and 9.0.0). The percentage degenerative area for the H\&E staining was analysed using ImageJ software.

\section{Results And Discussion}

\section{1) In vitro experiments}

a. MTT assay: MTT is a colorimetric assay that measures the reduction of yellow MTT by mitochondrial succinate dehydrogenase. The MTT enters the cells and passes into the mitochondria where it is reduced to an insoluble, coloured (dark purple) formazan product which is measured photometrically. Here, the percentage inhibition of the cells treated with rapa and vori increased in a time and concentration dependent manner.

On $12 \mathrm{~h}$ treatment with rapa at $10 \mu \mathrm{M}$, only $10 \%$ cells were inhibited, but $2 \mu \mathrm{M}$ of vori inhibited cells more than $20 \%$ and their combination treatment inhibited cells near to $40 \%$. At $20 \mu \mathrm{M}$ of rapa and $4 \mu \mathrm{M}$ of vori the cell growth was inhibited by less than $40 \%$, however their combination inhibited cell growth more than $50 \%$ (Fig. 2A). On $24 \mathrm{~h}$ treatment with rapa at a dose of $10 \mu \mathrm{M}, 20 \%$ inhibition was observed and for vori at $2 \mu \mathrm{M}$ it was nearly $35 \%$, however their combination inhibited cell growth near to $40 \%$. Further, $20 \mu \mathrm{M}$ rapa and $4 \mu \mathrm{M}$ vori alone inhibited $35 \%$ and $45 \%$ of cell growth respectively, however their combination drastically inhibited cell growth at about $70 \%$. Inhibition rate was increased to $90 \%$ upon increasing the dose of rapa to $40 \mu \mathrm{M}$ and vori $8 \mu \mathrm{M}$ (Fig. $2 \mathrm{~B})$. On $36 \mathrm{~h}$ treatment with rapa $(20 \mu \mathrm{M})$ and vori $(4 \mu \mathrm{M})$ inhibited cell growth more than $50 \%$ and their combination drastically inhibited growth by $80 \%$ (Fig. $2 \mathrm{C}$ ). Based on these results we have selected rapa, $20 \mu \mathrm{M}$; vori, $4 \mu \mathrm{M}$ for treatment in alone and rapa, $10 \mu \mathrm{M}$; vori, $2 \mu \mathrm{M}$ for combination treatment.

\section{b. Effect of rapa and vori on mRNA expression level of APP, BDNF, GDNF and NGF}

The mRNA expression of APP was increased in SH-SY5Y cells treated with high glucose and $A \beta_{1-42}$. However on treatment with rapa and vori in alone decreased the expression level of APP (rapa, ${ }^{*} P \leq 0.05$; vori, $\mathrm{P} \leq 0.05$ ). The combination of rapa and vori markedly down regulated the APP level with a significance of ${ }^{\star \star *} \mathrm{P} \leq 0.001$ in comparison with high glucose $+A \beta_{1-42}$ group. Moreover, the expression level of APP in combination group has been significantly decreased in comparison with rapa ( $\left.{ }^{*} P \leq 0.05\right)$ and vori ( $\left.{ }^{*} \mathrm{P} \leq 0.05\right)$ treatment in alone (Fig. 3A). Conversely, the BDNF, GDNF and NGF expression level was decreased in high glucose $+A \beta_{1-42}$ group. However their expression levels were up regulated on treatment with rapa and vori in alone. Interestingly in combination (rapa+vori) group the expression levels of BDNF $\left({ }^{\star \star \star} \mathrm{P} \leq 0.001\right), \mathrm{GDNF}\left({ }^{\star \star \star \star} \mathrm{P} \leq 0.0001\right)$ and NGF $\left.{ }^{\star \star \star \star} \mathrm{P} \leq 0.0001\right)$ were significantly up regulated when compared with the high glucose $+A \beta_{1-42}$ group. Further, all mRNA expression levels significantly up regulated in combination group on comparison with rapa and vori in alone, for BDNF: rapa, ${ }^{*} \mathrm{P} \leq 0.05$; vori, ${ }^{* \star} \mathrm{P} \leq 0.01$; for GDNF: rapa, ${ }^{* \star} \mathrm{P} \leq 0.01$; vori, ${ }^{* *} \mathrm{P} \leq 0.01$; for NGF: rapa, ${ }^{* \star *} \mathrm{P} \leq 0.001$; vori, ${ }^{* \star *} \mathrm{P} \leq 0.001$, (Fig. $3 \mathrm{~B}-$ 3D). 


\section{c. Effect of rapa and vori on mRNA expression level of beclin-1, LC3, LAMP2 and MAP2}

During AD pathogenesis, the levels of beclin-1, LC3, LAMP-2 are found to impair with disease progression leading to disruption in the autophagy machinery. Hence, in this regard we wanted to check the levels of beclin-1, LC3 and LAMP-2 in high glucose $+A \beta_{1-42}$ group and if these disrupted levels can be reversed after treatment with the combination of rapa and vori. Beclin-1 is a $60 \mathrm{kDa}$ protein playing a critical role in autophagy induction. It is known to control the initiating step in autophagosome assembly from preautophagic structures. LC3 is a reliable marker for autophagosomes while LAMP- 2 is critically involved in lysosomal stability and autophagy. MAP-2 is a cytoskeletal protein known to stabilize the microtubule assembly.

The mRNA expression levels of beclin-1, LC3, LAMP2 and MAP2 were significantly decreased in SH-SY5Y cells treated with high glucose $+A \beta_{1-42}$ group when compared to the control group. Conversely, the single drug treatments with rapa and vori increased the mRNA expression level of beclin-1 with a significance of ${ }^{\star \star *} \mathrm{P} \leq 0.001$ and ${ }^{\star *} \mathrm{P} \leq 0.01$ respectively, LC3 with a significance of ${ }^{\star \star *} \mathrm{P} \leq 0.001$, LAMP2 expression with a significance of ${ }^{* *} \mathrm{P} \leq 0.01$ and MAP2 expression with a significance of ${ }^{* *} \mathrm{P} \leq 0.01$ with respect to high glucose $+A \beta_{1-42}$ group. Interestingly, the expression levels of beclin1 $\left({ }^{\star \star \star \star} P \leq 0.0001\right), \operatorname{LC} 3\left({ }^{\star \star \star *} P \leq 0.0001\right)$, LAMP2 $\left({ }^{\star \star \star} \mathrm{P} \leq 0.001\right)$ and MAP2 $\left({ }^{\star \star \star} \mathrm{P} \leq 0.0001\right)$ were markedly up regulated in the combination group (rapa+vori) when compared to the high glucose $+A \beta_{1-42}$ group.

Further, the expression levels of mRNA in combination group were significantly up regulated on comparison with treatments alone. For Beclin-1, ${ }^{\star \star *} \mathrm{P} \leq 0.001$ (rapa and vori vs combination); for LC3, ${ }^{* *} \mathrm{P} \leq 0.01$ (rapa and vori vs combination); for LAMP-2, ${ }^{*} \mathrm{P} \leq 0.05$ (rapa and vori vs combination); and for MAP-2, ${ }^{* \star} \mathrm{P} \leq 0.01$ (rapa and vori vs combination) (Fig. 4A-4D).

\section{In-vivo experiments}

\section{a. Effect of HFD feeding on overall lipid profile for confirmation of IR condition}

Before proceeding with the estimations for AD progression, we first confirmed that the rats fed with HFD have become insulin resistant. For this purpose, we had performed the serum estimations of TC, TG and LDL levels and it was observed that a consecutive increase of TC, TG and LDL cholesterol was attained starting from week 4 up to week 8 . The TC $\left({ }^{\star \star \star *} P \leq 0.0001\right), T G\left({ }^{\star \star} P \leq 0.01\right)$ and LDL cholesterol $\left({ }^{\star *} P \leq 0.01\right)$ levels of HFD fed rats considerably increased as compared with the normal pellet diet (NPD) fed group (Supplementary Fig. 1A-1C) confirming the presence of IR condition.

\section{b. Morris water maze}

MWM is an internationally acclaimed and a well-accepted behavioural model to assess any cognitive abnormality and has been recognised as a gold standard model to evaluate AD pathology progression in rats. In the present study, we tested rats on this task and as per the anymaze tracking software, on the final day of training we found out that the IR rats and the IR induced AD rats displayed similar delay in 
locating the platform. However, the animals treated with rapa and vori alone faintly decreased the time duration to locate the hidden platform when compared with HFD+A $\beta_{1-42}$. Interestingly the rats treated with a combination of rapa and vori exhibited considerable improvement in locating the platform as compared to the HFD $+A \beta_{1-42}$ group with a significance of ${ }^{\star \star \star *} P \leq 0.0001$. Similar effect was observed during the probe trial where the combination group animals spent greater time near the target quadrant when compared to the HFD $+A \beta_{1-42}$ group with a significance of ${ }^{\star \star \star *} P \leq 0.0001$, but the groups treated with rapa and vori in alone spent considerably less time as compared to the HFD+A $\beta_{1-42}$ group in target quadrant with a significance of ${ }^{\star} \mathrm{P} \leq 0.05$ and ${ }^{\star *} \mathrm{P} \leq 0.01$ respectively.

Further, the combination treatment demonstrates significant improvement in the spatial memory of $\mathrm{HFD}+\mathrm{A} \beta_{1-42}$ group on comparison with the treatment in alone in MWM task ${ }^{\star *} \mathrm{P} \leq 0.01$, rapa vs combination; ${ }^{* *} \mathrm{P} \leq 0.01$ vori vs combination) and in probe trial ${ }^{* *} \mathrm{P} \leq 0.01$, rapa vs combination; ${ }^{*} \mathrm{P} \leq 0.05$, vori vs combination). Figure 5 shows the track plot for the $4^{\text {th }}$ day of MWM trial (Panel A) and probe trial (Panel B). In Figure 6A and 6B, the quantified bar diagram for the tracking of rat head for the final day of the MWM training (Panel A) and for probe trial (Panel B) is depicted.

\section{c. Effect of rapa and vori on mRNA expression level of APP, BDNF, GDNF and NGF}

The mRNA expression levels of APP was found to increase in HFD+A $\beta_{1-42}$ group with respect to the NPD group $\left({ }^{\star \star \star} \mathrm{P} \leq 0.0001\right)$. However, it was significantly decreased with rapa and vori treatment in alone $\left({ }^{\star *} \mathrm{P} \leq 0.01\right.$ for rapa; ${ }^{* \star} \mathrm{P} \leq 0.01$ for vori). However a marked decrease was observed in combined treatment with rapa and vori $\left({ }^{\star \star *} \mathrm{P} \leq 0.01\right)$ in comparison with $H F D+A \beta_{1-42}$ group (Fig. 7A). The BDNF, GDNF and NGF expression level were decreased in $\mathrm{HFD}+A \beta_{1-42}$ group with a significance of ${ }^{\star *} \mathrm{P} \leq 0.01,{ }^{* \star *} \mathrm{P} \leq 0.001$,

${ }^{* *} \mathrm{P} \leq 0.01$ respectively on comparison with NPD group. Besides, the treatment with rapa and vori in alone increased the mRNA expression level of BDNF $\left({ }^{\star \star \star} P \leq 0.001\right.$, rapa; ${ }^{\star \star \star} P \leq 0.001$, vori), GDNF $\left({ }^{\star \star *} \mathrm{P} \leq 0.001\right.$, rapa; ${ }^{* \star *} P \leq 0.0001$, vori), and NGF $\left({ }^{\star \star} P \leq 0.01\right.$, rapa; ${ }^{* \star} P \leq 0.001$, vori) with respect to HFD+A $\beta_{1-42}$ group. Interestingly in the combination group (rapa+vori), significant increase was observed for BDNF $\left({ }^{\star \star \star *} \mathrm{P} \leq 0.0001\right), \mathrm{GDNF}\left({ }^{\star \star \star \star} \mathrm{P} \leq 0.0001\right)$ and NGF $\left({ }^{\star \star \star *} \mathrm{P} \leq 0.0001\right)$ expression in comparison with HFD+A $\beta_{1-42}$ group (Fig. 7B-7D).

Further, the combination treatment shows significant positive alteration in all above mRNA expression levels as compared to the single treatment. For APP: ${ }^{* *} \mathrm{P} \leq 0.01$, rapa vs combination; ${ }^{*} \mathrm{P} \leq 0.05$ vori vs combination, for BDNF: ${ }^{*} \mathrm{P} \leq 0.05$, rapa vs combination; ${ }^{*} \mathrm{P} \leq 0.05$ vori vs combination, for GDNF: ${ }^{*} \mathrm{P} \leq 0.01$, rapa vs combination; ${ }^{*} \mathrm{P} \leq 0.05$ vori vs combination and for NGF: ${ }^{*} \mathrm{P} \leq 0.05$, rapa vs combination; ${ }^{*} \mathrm{P} \leq 0.05$ vori vs combination.

To further confirm the neuroprotective efficacy of rapa and vori on the levels of $A \beta_{1-42}, p T a u, B D N F, G D N F$, and NGF levels we performed ELISA in which the elevated level of $A \beta_{1-42}$ and $p T a u$ in HFD+A $\beta_{1-42}$ group was attenuated with rapa and vori treatment alone and in combination with marked significant change 
(Supplementary Fig. 2A-2B). Further the BDNF, GDNF, and NGF levels was decreased in HFD+A $\beta_{1-42}$ group with respect to NPD group, however that could be reversed with the combination treatment with rapa and vori. Hence, the results of the ELISA based assay significantly correlated with the RT-PCR assay (Supplementary Fig. 3A-3C).

\section{d. Effect of rapa and vori on mRNA expression level of beclin-1, LC3, LAMP-2 and MAP2}

The analysis of each group was based on response to fold change with respect to the control group. mRNA expression of beclin-1 $\left({ }^{\star \star \star} P \leq 0.0001\right)$. LC3 $\left({ }^{\star \star *} P \leq 0.001\right)$ and LAMP2 $\left({ }^{\star \star \star *} P \leq 0.0001\right)$ increased significantly in the HFD $+A \beta_{1-42}$ group when compared to the NPD group. However, beclin-1 expression levels were found to decrease on treatment with rapa and vori in alone $\left({ }^{\star \star} \mathrm{P} \leq 0.001\right.$ and ${ }^{\star \star} \mathrm{P} \leq 0.01$ respectively) whereas a significant decrease was found in the group treated with rapa and vori in combination when compared with $\mathrm{HFD}+\mathrm{A} \beta_{1-42}$ group, ${ }^{* \star \star *} \mathrm{P} \leq 0.0001$ (Fig. 8A). On treatment with rapa and vori in alone the level of LC3 was decreased $\left({ }^{\star *} \mathrm{P} \leq 0.01\right.$, rapa; ${ }^{*} \mathrm{P} \leq 0.05$, vori). However, the combination treatment with rapa and vori significantly ameliorated the expression levels of LC3 when compared with the disease group, ${ }^{\star \star \star} \mathrm{P} \leq 0.001$ (Fig. 8B). Similarly, decrease in LAMP-2 mRNA expression was found upon treatment with rapa and vori in alone $\left({ }^{\star *} \mathrm{P} \leq 0.01\right.$, rapa; ${ }^{*} \mathrm{P} \leq 0.05$, vori) and markedly in combination $\left({ }^{\star \star *} \mathrm{P} \leq 0.001\right)$ when compared to the HFD+A $\beta_{1-42}$ group (Fig. 8C). A considerable decrease in the mRNA expression of MAP2 was observed for the HFD $+A \beta_{1-42}$ group when compared to the NPD group $\left({ }^{\star * *} \mathrm{P} \leq 0.001\right)$, which was effectively restored by the combination treatment with rapa and vori $\left({ }^{\star \star \star *} \mathrm{P} \leq 0.0001\right)$, and treatment in alone, ${ }^{\star \star} \mathrm{P} \leq 0.01$, rapa; ${ }^{\star *} \mathrm{P} \leq 0.01$, vori (Fig. 8D). Further, the combination of rapa and vori significantly reduced the expression level of beclin-1, LC3, LAMP-2 and MAP2 when compared with its treatment in alone. For beclin- 1 : ${ }^{*} \mathrm{P} \leq 0.05$, rapa vs combination; ${ }^{* *} \mathrm{P} \leq 0.01$, vori vs combination, for LC3: ${ }^{*} \mathrm{P} \leq 0.05$, rapa vs combination; ${ }^{*} \mathrm{P} \leq 0.01$, vori vs combination, for LAMP- 2 : ${ }^{*} \mathrm{P} \leq 0.05$, rapa vs combination; ${ }^{* *} \mathrm{P} \leq 0.01$, vori vs combination, and for MAP2: ${ }^{* *} \mathrm{P} \leq 0.01$, rapa vs combination; ${ }^{* *} \mathrm{P} \leq 0.01$, vori vs combination.

\section{e. Effect of rapa and vori on histone $\mathrm{H} 3$ acetylation}

Epigenetic modulation is a major part occurring during AD pathogenesis which is also known to regulate expression of numerous autophagy related proteins. Hence, we explored the level of global histone H3 acetylation to check the deleterious effect of $A \beta_{1-42}$ and effective reversal after treatment with rapa and vori. Intriguingly, we observed that the group of $H F D+A \beta_{1-42}$ had reduced $H 3$ acetylation levels $\left({ }^{\star \star \star *} \mathrm{P} \leq 0.0001\right)$ compared to the NPD group which was significantly increased after treatment with rapa and vori in alone ( ${ }^{\star} \mathrm{P} \leq 0.05$ and ${ }^{\star \star \star} \mathrm{P} \leq 0.001$ respectively). Further, in combination treatment (rapa+vori) a marked significant increase of $\mathrm{H} 3$ acetylation was observed when compared to the HFD+A $\beta_{1-42}$ group $\left({ }^{\star * \star *} \mathrm{P} \leq 0.0001\right)$. Moreover, the increase in $\mathrm{H} 3$ acetylation in combination group was significant when compared with rapa and vori in alone was found to be ${ }^{\star \star *} \mathrm{P} \leq 0.001$ and ${ }^{* \star} \mathrm{P} \leq 0.01$ respectively (Fig. 9). 


\section{f. Histopathological analysis}

Histochemical analysis of hippocampal DG and CA1 region shows that the count of pyknotic neurones, vacuolization, and cell blebbing in the HFD+A $\beta_{1-42}$ group was higher than the NPD group which are indicated with red arrows. This HFD and $A \beta_{1-42}$ induced degenerated hippocampus area was significantly attenuated after treatment with combined form of rapa and vori as evidenced from the considerably reduced count for pyknotic neurones and vacuolization in DG region $\left({ }^{\star *} \mathrm{P} \leq 0.01\right.$ for rapa alone, ${ }^{\star \star} \mathrm{P} \leq 0.01$ for vori alone and ${ }^{\star \star \star *} \mathrm{P} \leq 0.0001$ for combination) and in CA1 region $\left({ }^{\star *} \mathrm{P} \leq 0.01\right.$ for rapa alone, ${ }^{* \star *} \mathrm{P} \leq 0.001$ for vori alone and ${ }^{\star \star * *} \mathrm{P} \leq 0.0001$ for combination) indicated with green arrows (Fig. 10, 11A and 11B). Moreover the neurodegeneration in combination group was significantly lower as compared with the treatment in alone, For DG region: ${ }^{* \star \star} \mathrm{P} \leq 0.0001$, rapa vs combination; ${ }^{\star \star \star *} \mathrm{P} \leq 0.0001$, vori vs combination, for $\mathrm{CA} 1$ region: ${ }^{* \star *} \mathrm{P} \leq 0.0001$, rapa vs combination; ${ }^{* \star *} \mathrm{P} \leq 0.001$, vori vs combination, (Fig. $11 \mathrm{~A}$ and $\mathrm{B}$ ).

IR induced AD complications continue to emerge as a global threat as the exact pathological cause is still unknown and hence therapies to halt the disease progression has failed to reach the market. The only available treatments till now are based on a symptomatic approach. Pathologically characterized as $A \beta$ accumulation and hyperphosphorylation of tau protein particularly in the hippocampal region of the brain, $A D$ is primarily known to affect cognitive functions of an individual.

In addition to the pathological connection between IR and $A D$, what drives misfolding of $A \beta$ remains enigmatic, but irrespective of the cause removing these misfolded proteins with time is crucial for maintaining a healthy neuronal environment. Autophagy is a self-conserved mechanism popular for its role as a flusher of damaged and misfolded proteins. Recent research has focused on enhancement of neuronal autophagy as an effective therapeutic approach to remove aggregated proteins proving to be a boon for neurodegenerative disorders. Autophagy is an oriented mechanism that demands the aid of numerous autophagy related proteins in completing the overall process. In turn, these autophagy related proteins are believed to be under the control of post translational histone modifications. Studies suggest that histone deacetylase inhibition elicits neuroprotection in several models of $A D$ and Parkinson disease (PD). Hence, in the current study we mainly focused on investigating the combined efficacy of vori, a widely used pan HDACi, and a potent autophagy inducer, rapa in ameliorating IR induced AD pathology both in-vitro and in-vivo.

Initially, MTT assay on SH-SY5Y cell line was performed and a 20 and $35 \%$ of cell growth was inhibited with rapa and vori at a dose of $10 \mu \mathrm{M}$ and $2 \mu \mathrm{M}$ respectively and, $40 \%$ with their combination dose. Again, $20 \mu \mathrm{M}$ of rapa and $4 \mu \mathrm{M}$ of vori inhibited cell growth by $35 \%$ and $45 \%$ respectively and their combination inhibited $70 \%$ of cell growth. mRNA analysis of relevant autophagy related proteins along with proteins known to affect $A D$ pathogenesis was conducted to explore the neuroprotective efficacy of rapa and vori alone as well as in combination in high glucose and $A \beta_{1-42}$ treated SH-SY5Y cells. mRNA analysis revealed that the expression level of BDNF, NGF, GDNF, beclin-1, LC3, LAMP-2 and MAP2 were upregulated 
and the expression of APP was downregulated for the combination group (rapa+vori) when compared to the high glucose $+A \beta_{1-42}$ treated group as well as upon comparison with the drugs treated alone.

Later we proceeded with a battery of behavioural, biochemical and histological analysis to prove our hypothesis that rapa and vori in combination has the capacity to mitigate IR induced AD symptoms in wistar rats. Firstly, we wanted to check the TC, TG and LDL levels to confirm the IR state of the rodents. Our lab have already successfully reported and validated the HFD model giving rise to IR condition in rats(Sharma \& Taliyan, 2018). However, before proceeding with the administration of $A \beta_{1-42}$ peptide into the rodent brain we wanted to make sure that the rats have successfully developed IR condition. What we observed was that the levels of TC, TG and LDL were found to be up regulated in the HFD group when compared to the NPD group. All these estimations were performed on a weekly basis for 8 weeks and a steep and continuous increase was observed in the serum TC, TG and LDL levels for the rats fed with the HFD which was not the case observed in the NPD group. These estimations were only performed for the NPD and HFD group with the intention to confirm the IR state of the rodents.

After confirming the IR state the animals were administered with $A \beta_{1-42}$ peptide directly into the lateral cerebral ventricles. Post-surgical care was provided and treatment was commenced with rapa and vori from the third day post $A \beta_{1-42}$ administration, i.p. once daily for 28days. On completion of the treatment, MWM was performed to assess any sort of cognitive anomaly where we found out that the latency to locate the target platform for the HFD group induced with $A \beta_{1-42}$ was much higher as compared to the group treated with a combination of rapa and vori. Favourable results for the combination group were also being observed during the probe trial.

Further, in vivo mRNA analysis for the levels of APP, BDNF, GDNF, NGF, and beclin-1, LC3, LAMP-2 and MAP2 revealed that except for APP, the levels of BDNF, GDNF, NGF and MAP2 up regulated in the combination treatment group when compared to the HFD $+A \beta_{1-42}$ group. Similarly, the levels of APP significantly down regulated in the treated group with both rapa and vori when compared to the HFD+A $\beta_{1}$. 42 group. Moreover, the impaired levels of beclin-1, LC3 and LAMP-2 in the disease group seem to considerably improve after treatment with the combination of rapa and vori.

We also performed ELISA estimations of $A \beta_{42}$, ptau, BDNF, GDNF and NGF and observed that the $H F D+A \beta_{1-42}$ group had elevated levels of $A \beta$ and ptau and decreased levels of BDNF, GDNF and NGF. These effects were found to reverse after treatment with a combination of rapa and vori.

Lastly, histological analysis of both the DG and CA1 region using H\&E stain exposed significant pyknotic neuronal count, considerable vacuolization, cell infiltration etc with resultant degenerated neurones for both the groups of HFD alone and HFD with the $A \beta_{1-42}$ group. However, after treatment with combination of rapa and vori, the percentage of neurodegenerative area as analysed by imageJ software declined, eliciting possible neuroprotection.

\section{Conclusion}


IR associated $A D$ poses a great threat to the economy worldwide as cases continue to rise with no available therapeutic cure except symptomatic management. Autophagy inducers have recently evolved as a potent neuroprotective target delivering considerable efficacy in preclinical AD models but its usage is limited by factors such as over-accumulation of misfolded proteins leading to failure in its efficacy. However, when combined with HDACi, this limitation is overcome which can effectively emerge as a favourable therapeutic option for IR induced AD. Hence in the current study, we used a leading autophagy inducer, namely rapa alone as well as in combination with vori for the treatment of HFD induced AD which is the first study performed to the best of our knowledge and its preliminary outcomes are satisfactory enough to further explore possible therapeutic outcome in this area.

\section{Declarations}

\section{Acknowledgement}

Authors are thankful to BITS Pilani, Pilani Campus, Rajasthan, India and Taipei Medical University, Taipei, Taiwan for providing support for the current study.

\section{Declarations}

\section{Funding}

No funding was received for conducting this study.

\section{Conflict of interest}

The authors declare no conflict of interest.

\section{Availability of data and material}

All data generated or analysed during this study are incorporated in the manuscript file and in supplementary file. There was no immunoblot analysis performed in this study.

\section{Code availability}

Not applicable

\section{Author contributions}

Violina Kakoty, Rajeev Taliyan, Sunil Kumar Dubey, Chih Hao Yang designed the current research work. Violina Kakoty and Sarathlal K C performed experiments, analysed and interpreted the data and wrote the manuscript, Rajeev Taliyan approved the final version of the manuscript.

\section{Abbreviations}




\begin{tabular}{|c|c|c|}
\hline$A D$ & - & Alzheimer disease \\
\hline$A \beta$ & - & Amyloid beta \\
\hline BDNF & - & Brain derived neurotrophic factor \\
\hline cDNA & - & Complementary deoxyribonucleic acid \\
\hline DMEM/F12 & - & Dulbecco's Modified Eagle's Medium/ Ham's F-12 \\
\hline DMSO & - & Dimethyl sulfoxide \\
\hline FBS & - & Fetal bovine serum \\
\hline GAPDH & - & Glyceraldehyde 3-phosphate dehydrogenase \\
\hline GDNF & - & Glial cell derived neurotrophic factor \\
\hline HDACi & - & Histone deacetylase inhibitor \\
\hline HFD & - & High fat diet \\
\hline IAEC & - & Institutional Animal Ethics Committee \\
\hline IR & - & Insulin resistance \\
\hline LAMP-2 & - & Lysosome-associated membrane protein 2 \\
\hline LC3-II & - & $\begin{array}{l}\text { Microtubule-associated protein 1A/1B-light chain 3- } \\
\text { phosphatidylethanolamine conjugate }\end{array}$ \\
\hline LDL & - & Low density lipoprotein \\
\hline MAP2 & - & Microtubule associated protein 2 \\
\hline mTOR/mTORC1/mTORC2 & - & Mammalian target of rapamycin/complex $1 /$ complex 2 \\
\hline MTT & - & 3-(4, 5dimethythiazol-2-yl) 2, 5-diphenyl tetrazolium bromide \\
\hline MWM & - & Morris water maze \\
\hline NFTs & - & Neurofibrillary tangles \\
\hline NGF & - & Neuronal growth factor \\
\hline PBS & - & Phosphate buffered saline \\
\hline qPCR & - & Real-time quantitative polymerase chain reaction \\
\hline RAM & - & Radial arm maze \\
\hline Rapa & - & Rapamycin \\
\hline RNA & - & Ribonucleic acid \\
\hline STZ & - & Streptozotocin \\
\hline T2DM & - & Type 2 diabetes mellitus \\
\hline
\end{tabular}




\begin{tabular}{|c|c|}
\hline TC & - Total cholesterol \\
\hline TG & - Triglycerides \\
\hline ULK1 & - $\quad$ Unc51-like kinase 1 \\
\hline Vori & - Vorinostat \\
\hline
\end{tabular}

\section{References}

Boles, A., Kandimalla, R., \& Reddy, P. H. (2017). Dynamics of diabetes and obesity: epidemiological perspective. Biochimica et Biophysica Acta (BBA)-Molecular Basis of Disease, 1863(5), 1026-1036.

Chen, J.-C., Hsu-Chou, H., Lu, J.-L., Chiang, Y.-C., Huang, H.-M., Wang, H.-L., Wu, T., Liao, J.-J., \& Yeh, T.-S. (2005). Down-regulation of the glial glutamate transporter GLT-1 in rat hippocampus and striatum and its modulation by a group III metabotropic glutamate receptor antagonist following transient global forebrain ischemia. Neuropharmacology, 49(5), 703-714.

Classics Lowry, O., Rosebrough, N., Farr, A., \& Randall, R. (1951). Protein measurement with the Folin phenol reagent. J Biol Chem, 193, 265-275.

Ferreira, L. S. S., Fernandes, C. S., Vieira, M. N. N., \& De Felice, F. G. (2018). Insulin resistance in Alzheimer's disease. Frontiers in Neuroscience, 12, 830.

Füllgrabe, J., Lynch-Day, M. A., Heldring, N., Li, W., Struijk, R. B., Ma, Q., Hermanson, O., Rosenfeld, M. G., Klionsky, D. J., \& Joseph, B. (2013). The histone H4 lysine 16 acetyltransferase hMOF regulates the outcome of autophagy. Nature, 500(7463), 468-471.

Guertin, D. A., Stevens, D. M., Thoreen, C. C., Burds, A. A., Kalaany, N. Y., Moffat, J., Brown, M., Fitzgerald, K. J., \& Sabatini, D. M. (2006). Ablation in mice of the mTORC components raptor, rictor, or mLST8 reveals that mTORC2 is required for signaling to Akt-FOXO and PKC\$a\$, but not S6K1. Developmental Cell, 11(6), 859-871.

J Spielman, L., Bahniwal, M., P Little, J., G Walker, D., \& Klegeris, A. (2015). Insulin modulates in vitro secretion of cytokines and cytotoxins by human glial cells. Current Alzheimer Research, 12(7), 684-693.

Jahn, H. (2013). Memory loss in Alzheimer's disease. Dialogues in Clinical Neuroscience, 15(4), 445.

K C, S., Kakoty, V., Venkata Krishna, K., Kumar Dubey, S., Chitkara, D., \& Taliyan, R. (2021). Neuroprotective Efficacy of Co-Encapsulated Rosiglitazone and Vorinostat Nanoparticle on Streptozotocin Induced Mice Model of Alzheimer Disease. ACS Chemical Neuroscience, $O(0)$.

https://doi.org/10.1021/acschemneuro.1c00022 
Khan, M., Rutten, B. P. F., \& Kim, M. O. (2019). MST1 regulates neuronal cell death via JNK/Casp3 signaling pathway in HFD mouse brain and HT22 cells. International Journal of Molecular Sciences, 20(10), 2504.

Krishna, K. V., Saha, R. N., \& Dubey, S. K. (2020). Biophysical, Biochemical, and Behavioral Implications of ApoE3 Conjugated Donepezil Nanomedicine in a A\$\$\$1-42 Induced Alzheimer's Disease Rat Model. ACS Chemical Neuroscience, 11(24), 4139-4151.

Labandeira-Garcia, J. L., Costa-Besada, M. A., Labandeira, C. M., Villar-Cheda, B., \& Rodr\'\iguez-Perez, A. I. (2017). Insulin-like growth factor-1 and neuroinflammation. Frontiers in Aging Neuroscience, 9, 365.

Lu, Z., Liu, F., Chen, L., Zhang, H., Ding, Y., Liu, J., Wong, M., \& Zeng, L.-H. (2015). Effect of chronic administration of low dose rapamycin on development and immunity in young rats. PloS One, 10(8), e0135256.

M Ashraf, G., H Greig, N., A Khan, T., Hassan, I., Tabrez, S., Shakil, S., A Sheikh, I., K Zaidi, S., Akram, M., R Jabir, N., \& others. (2014). Protein misfolding and aggregation in Alzheimer's disease and type 2 diabetes mellitus. CNS \& Neurological Disorders-Drug Targets (Formerly Current Drug Targets-CNS \& Neurological Disorders), 13(7), 1280-1293.

Marques, S., \& Outeiro, T. F. (2013). Epigenetics in Parkinson's and Alzheimer's diseases. In Epigenetics: Development and Disease (pp. 507-525). Springer.

Meng, J., Li, Y., Camarillo, C., Yao, Y., Zhang, Y., Xu, C., \& Jiang, L. (2014). The anti-tumor histone deacetylase inhibitor SAHA and the natural flavonoid curcumin exhibit synergistic neuroprotection against amyloid-beta toxicity. PLoS One, 9(1), e85570.

Mizushima, N. (2010). The role of the Atg1/ULK1 complex in autophagy regulation. Current Opinion in Cell Biology, 22(2), 132-139.

Morris, R. (1984). Developments of a water-maze procedure for studying spatial learning in the rat. Journal of Neuroscience Methods, 11(1), 47-60.

Mullins, R. J., Diehl, T. C., Chia, C. W., \& Kapogiannis, D. (2017). Insulin resistance as a link between amyloid-beta and tau pathologies in Alzheimer's disease. Frontiers in Aging Neuroscience, 9, 118.

Ozansoy, M., Ozansoy, M. B., Yulug, B., Cankaya, S., Kilic, E., Goktekin, S., \& Kilic, U. (2020). Melatonin affects the release of exosomes and tau-content in in vitro amyloid-beta toxicity model. Journal of Clinical Neuroscience, 73, 237-244.

Sarathlal, K. C., Kakoty, V., Marathe, S., Chitkara, D., \& Taliyan, R. (2020). Exploring the Neuroprotective Potential of Rosiglitazone Embedded Nanocarrier System on Streptozotocin Induced Mice Model of Alzheimer's Disease. Neurotoxicity Research, 1-16. 
Sarbassov, D. D., Ali, S. M., \& Sabatini, D. M. (2005). Growing roles for the mTOR pathway. Current Opinion in Cell Biology, 17(6), 596-603.

Schotta, G., Lachner, M., Sarma, K., Ebert, A., Sengupta, R., Reuter, G., Reinberg, D., \& Jenuwein, T. (2004). A silencing pathway to induce $\mathrm{H} 3-\mathrm{K} 9$ and $\mathrm{H} 4-\mathrm{K} 20$ trimethylation at constitutive heterochromatin. Genes \& Development, 18(11), 1251-1262.

Selman, C., Tullet, J. M. A., Wieser, D., Irvine, E., Lingard, S. J., Choudhury, A. I., Claret, M., Al-Qassab, H., Carmignac, D., Ramadani, F., \& others. (2009). Ribosomal protein S6 kinase 1 signaling regulates mammalian life span. Science, 326(5949), 140-144.

Sharma, S., \& Taliyan, R. (2014). Neuroprotective role of Indirubin-3'-monoxime, a GSK\$ $\beta \$$ inhibitor in high fat diet induced cognitive impairment in mice. Biochemical and Biophysical Research Communications, 452(4), 1009-1015.

Sharma, S., \& Taliyan, R. (2015). Synergistic effects of GSK-3\$ $\beta$ \$ and HDAC inhibitors in intracerebroventricular streptozotocin-induced cognitive deficits in rats. Naunyn-Schmiedeberg's Archives of Pharmacology, 388(3), 337-349.

Sharma, S., \& Taliyan, R. (2016). Epigenetic modifications by inhibiting histone deacetylases reverse memory impairment in insulin resistance induced cognitive deficit in mice. Neuropharmacology, 105, 285-297.

Sharma, S., \& Taliyan, R. (2018). High fat diet feeding induced insulin resistance exacerbates 6-OHDA mediated neurotoxicity and behavioral abnormalities in rats. Behavioural Brain Research, 351, 17-23.

Sharma, S., Taliyan, R., \& Ramagiri, S. (2015). Histone deacetylase inhibitor, trichostatin A, improves learning and memory in high-fat diet-induced cognitive deficits in mice. Journal of Molecular Neuroscience, 56(1), 1-11.

Sharma, S., Taliyan, R., \& Singh, S. (2015). Beneficial effects of sodium butyrate in 6-OHDA induced neurotoxicity and behavioral abnormalities: Modulation of histone deacetylase activity. Behavioural Brain Research, 291, 306-314.

Spilman, P., Podlutskaya, N., Hart, M. J., Debnath, J., Gorostiza, O., Bredesen, D., Richardson, A., Strong, R., \& Galvan, V. (2010). Inhibition of mTOR by rapamycin abolishes cognitive deficits and reduces amyloid-\$ $\beta$ \$ levels in a mouse model of Alzheimer's disease. PloS One, 5(4), e9979.

Srinivasan, K., Viswanad, B., Asrat, L., Kaul, C. L., \& Ramarao, P. (2005). Combination of high-fat diet-fed and low-dose streptozotocin-treated rat: a model for type 2 diabetes and pharmacological screening. Pharmacological Research, 52(4), 313-320.

Wend, P., Fang, L., Zhu, Q., Schipper, J. H., Loddenkemper, C., Kosel, F., Brinkmann, V., Eckert, K., Hindersin, S., Holland, J. D., \& others. (2013). Wnt/\$ $\beta \$$-catenin signalling induces MLL to create epigenetic changes 
in salivary gland tumours. The EMBO Journal, 32(14), 1977-1989.

Yang, Y., Wu, Y., Zhang, S., \& Song, W. (2013). High glucose promotes A\$ $\beta \$$ production by inhibiting APP degradation. PloS One, 8(7), e69824.

Zeng, Z., Sarbassov, D. D., Samudio, I. J., Yee, K. W. L., Munsell, M. F., Ellen Jackson, C., Giles, F. J., Sabatini, D. M., Andreeff, M., \& Konopleva, M. (2007). Rapamycin derivatives reduce mTORC2 signaling and inhibit AKT activation in AML. Blood, 109(8), 3509-3512.

\section{Figures}

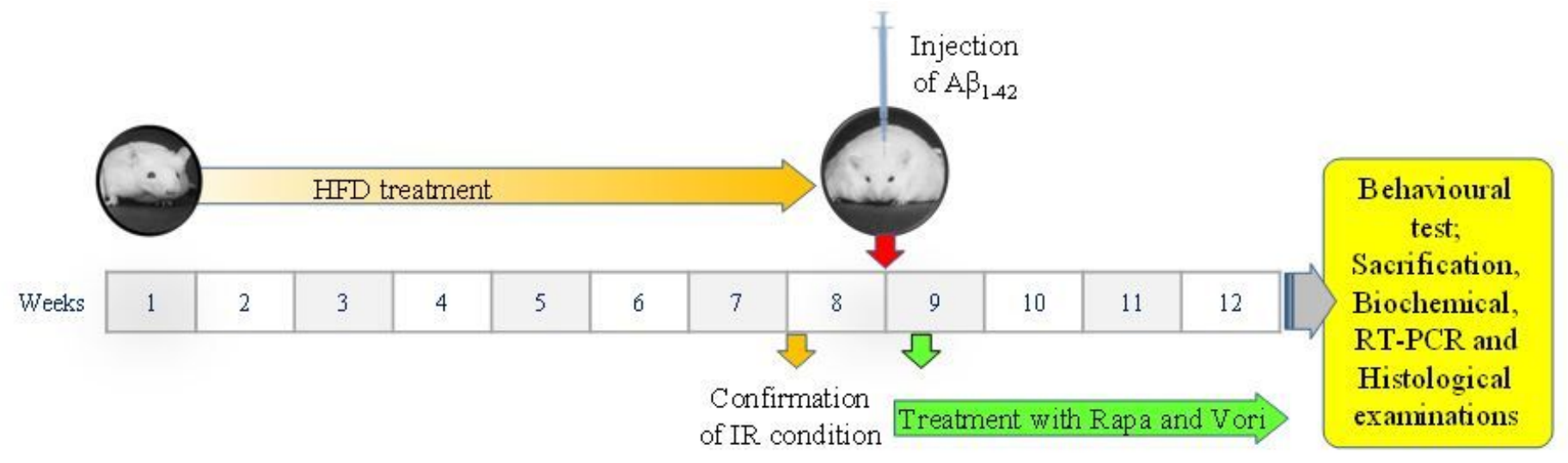

Figure 1

In-vivo experimental regimen.
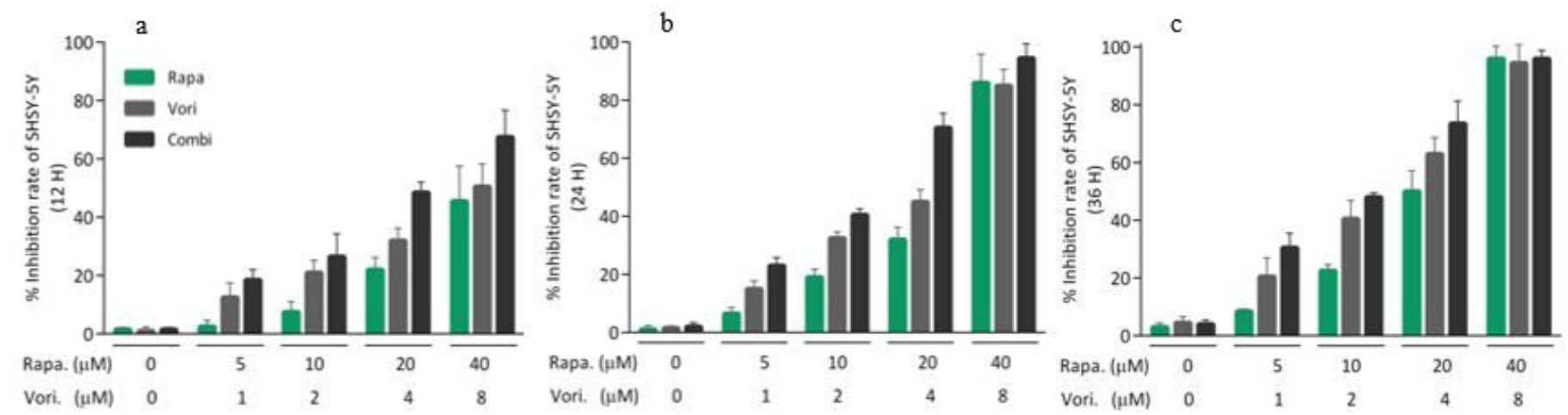

Figure 2

Percentage cell inhibition after treatment with various concentrations of rapa and vori alone and in combination for (a) 12h, (b) 24h, and (c) 36h. 
a
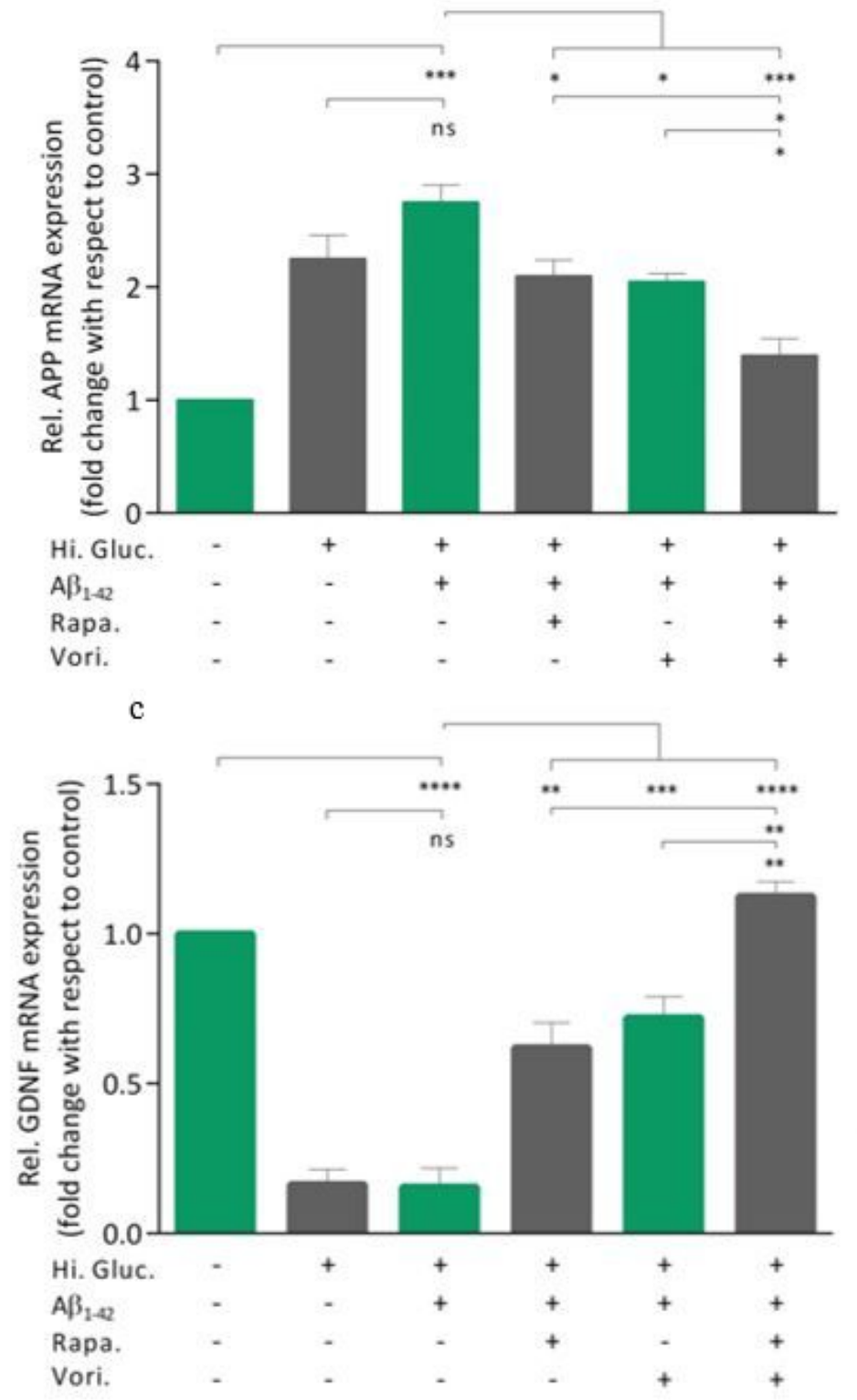

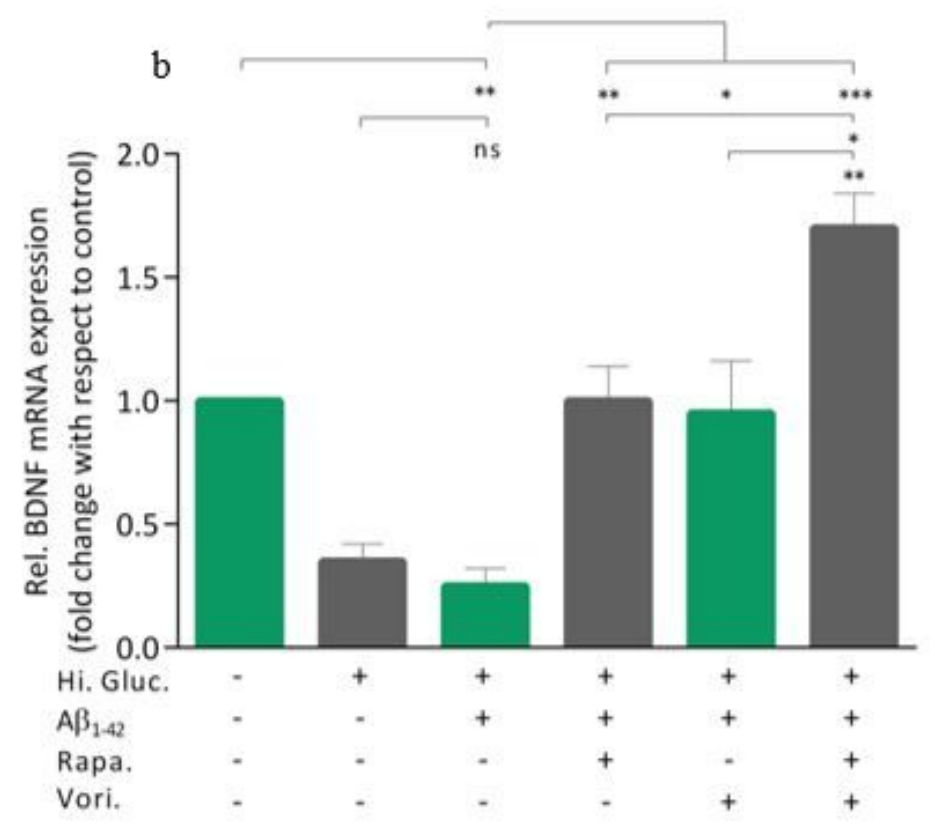

d

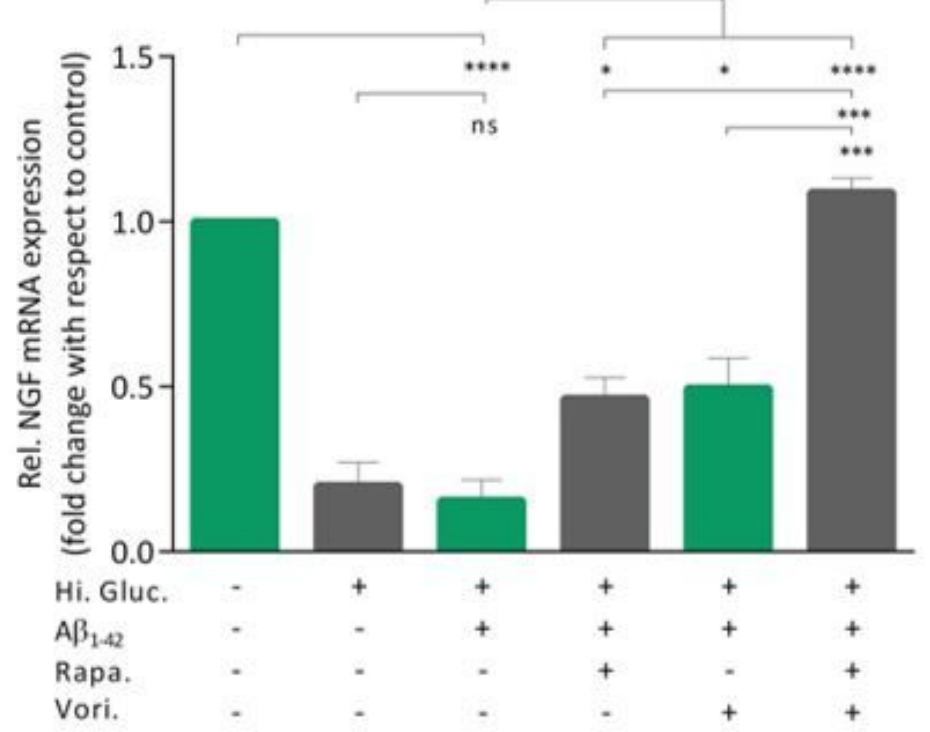

Figure 3

Effect of rapa and vori on (a) APP, (b) BDNF, (c) GDNF, and (d) NGF on SH-SY5Y cell. Values represent Mean $\pm S D ; * P \leq 0.05,{ }^{*} P \leq 0.01,{ }^{*} * * P \leq 0.001, * \star \star \star P \leq 0.0001$ and ns-non significant, $(+)=$ with treatment and $(-)=$ without treatment. 

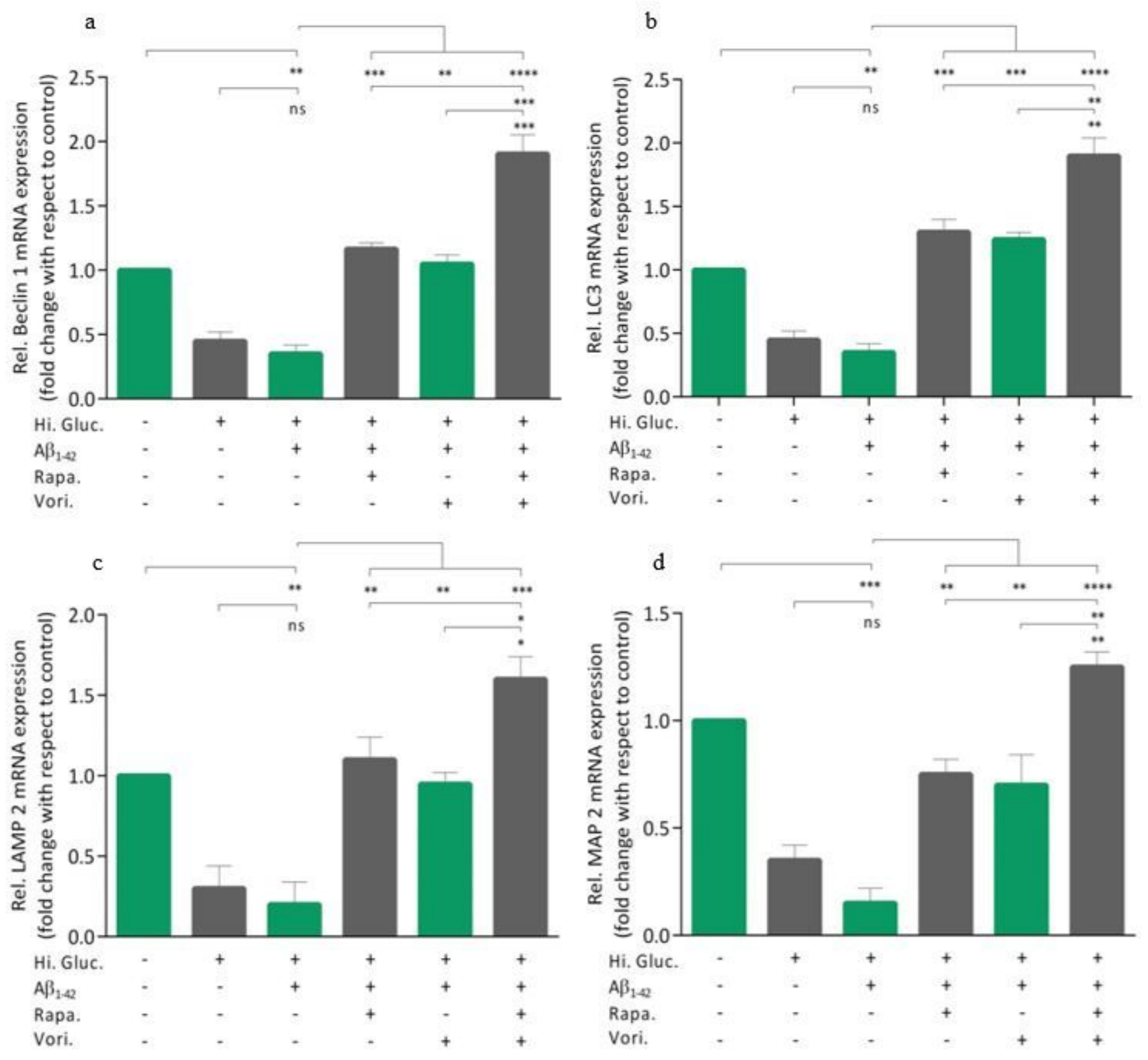

Figure 4

Effect of rapa and vori on (a) beclin-1, (b) LC3, (c) LAMP2, and (d) MAP2 on SH-SY5Y cell. Values

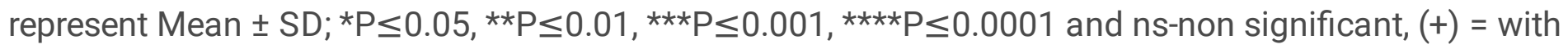
treatment and $(-)=$ without treatment. 


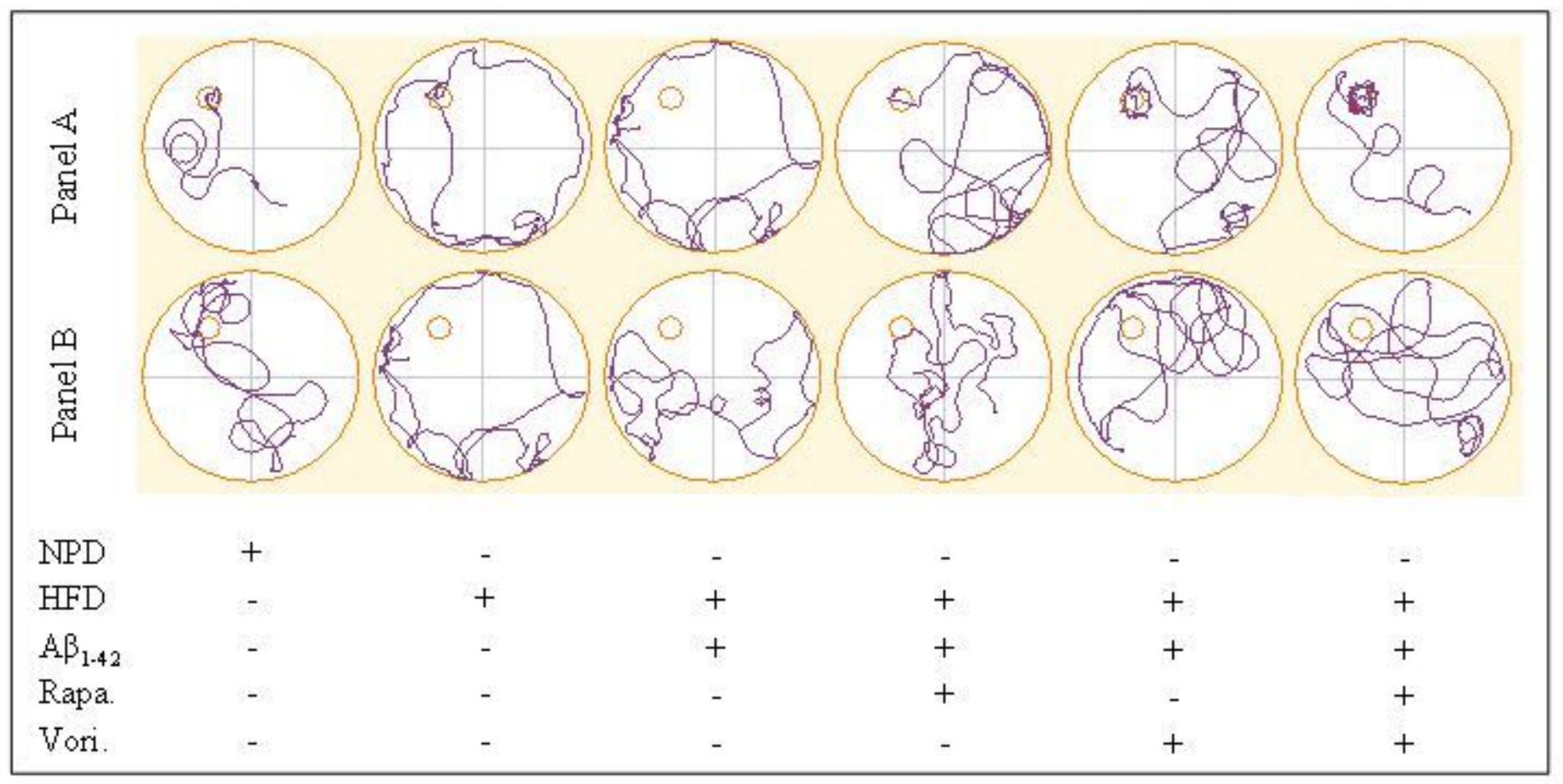

\section{Figure 5}

Track Plot for MWM experiment: Panel A: track plot on 4th day of trial, Panel B: track plot for probe trial, $(+)=$ with treatment and $(-)=$ without treatment.
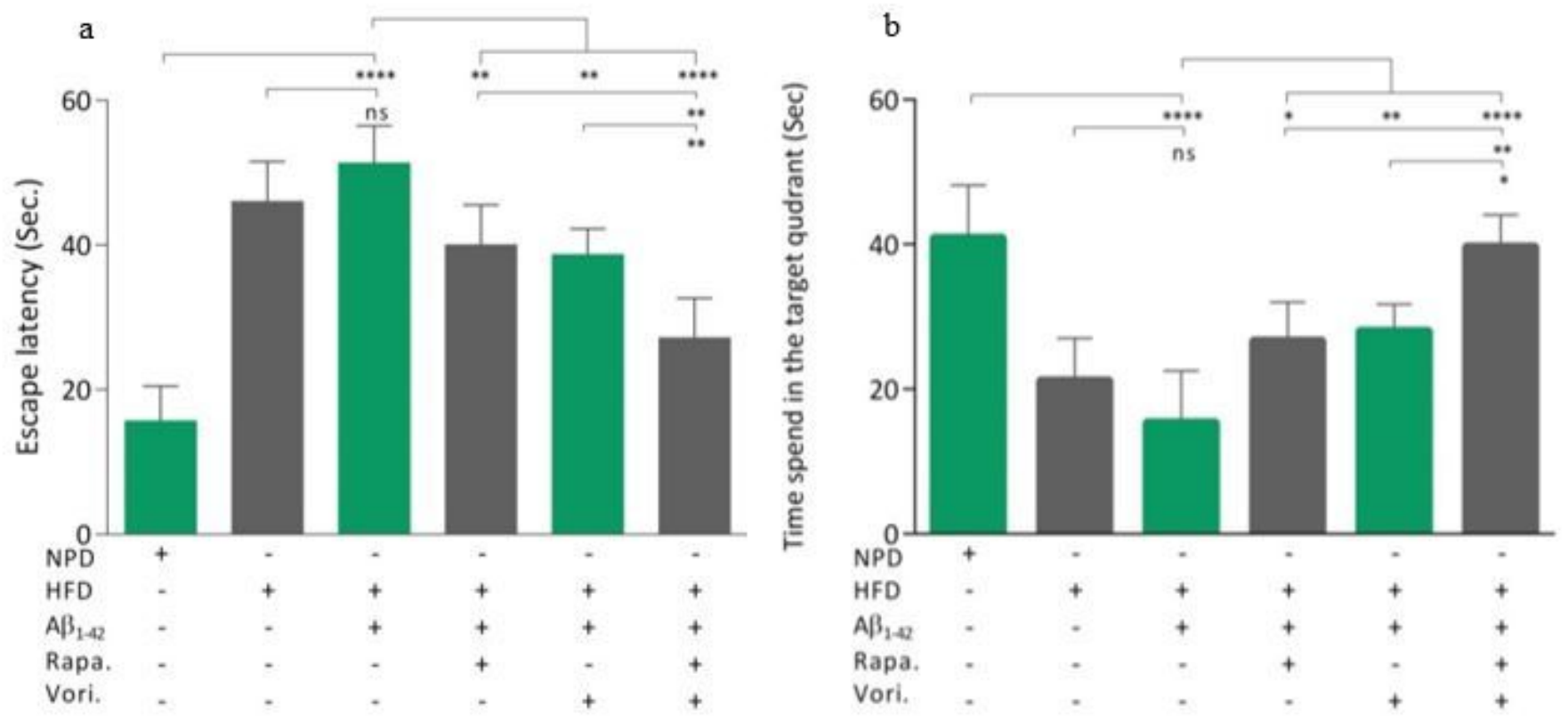

Figure 6

Effect of rapa and vori on MWM test (a) Spatial navigation task, and (b) Probe trial. Values represent Mean \pm SD; $* P \leq 0.05, * * P \leq 0.01, * \star * P \leq 0.001, * \star * * P \leq 0.0001,(+)=$ with treatment and $(-)=$ without 
treatment.
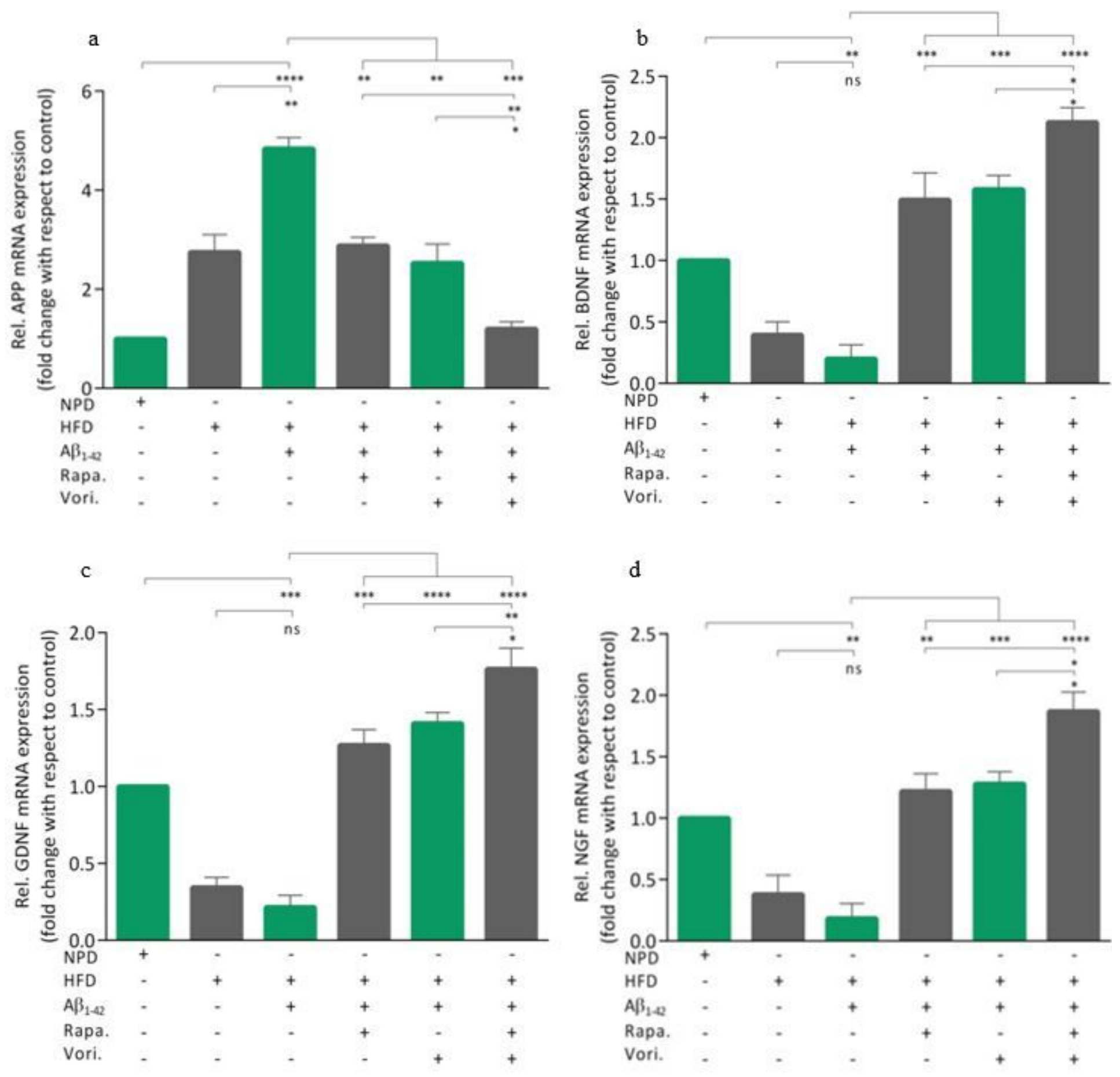

Figure 7

Effect of rapa and vori on (a) APP, (b) BDNF, (c) GDNF, and (d) NGF. Values represent Mean \pm SD; ${ }^{\star} P \leq 0.05,{ }^{*} P \leq 0.01,{ }^{\star \star \star} P \leq 0.001,{ }^{\star * \star \star} P \leq 0.0001$, ns-non significant, $(+)=$ with treatment and $(-)=$ without treatment. 

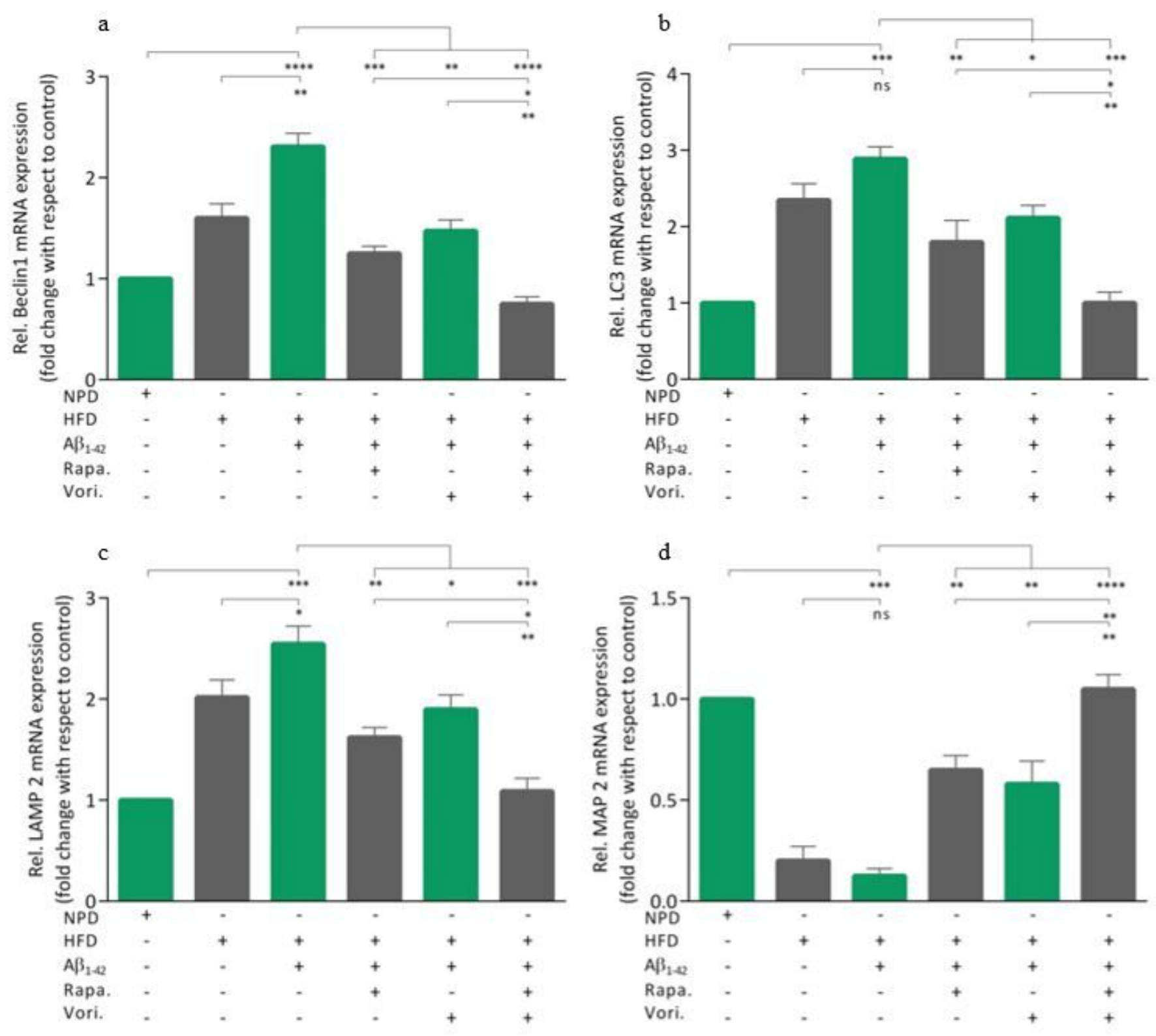

Figure 8

Effect of rapa and vori on (a) Beclin-1, (b) LC3, (c) LAMP-2, and (d) MAP2. Values represent Mean \pm SD; ${ }^{*} \mathrm{P} \leq 0.05,{ }^{* *} \mathrm{P} \leq 0.01,{ }^{* *} \mathrm{P} \leq 0.001,{ }^{* * *} \mathrm{P} \leq 0.0001$, ns-non significant, $(+)=$ with treatment and $(-)=$ without treatment. 


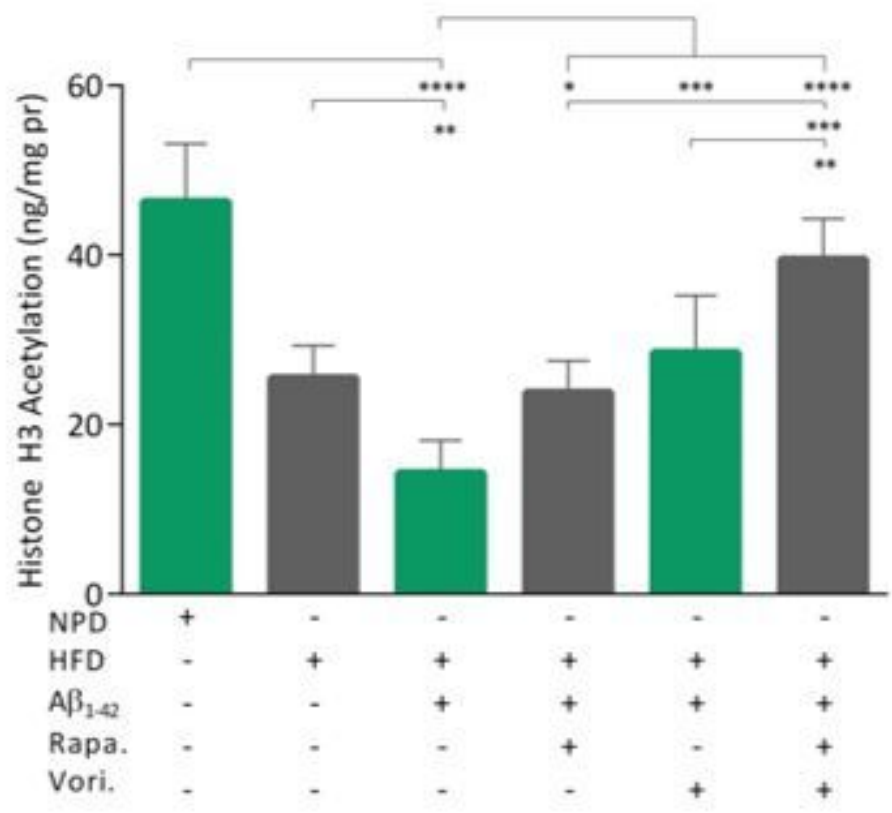

Figure 9

Effect of rapa and vori on histone $\mathrm{H} 3$ acetylation level. Values represent Mean $\pm S D ; * P \leq 0.05, * * P \leq 0.01$, ${ }^{\star \star \star} P \leq 0.001,{ }^{\star \star \star \star} P \leq 0.0001,(+)=$ with treatment and $(-)=$ without treatment. 


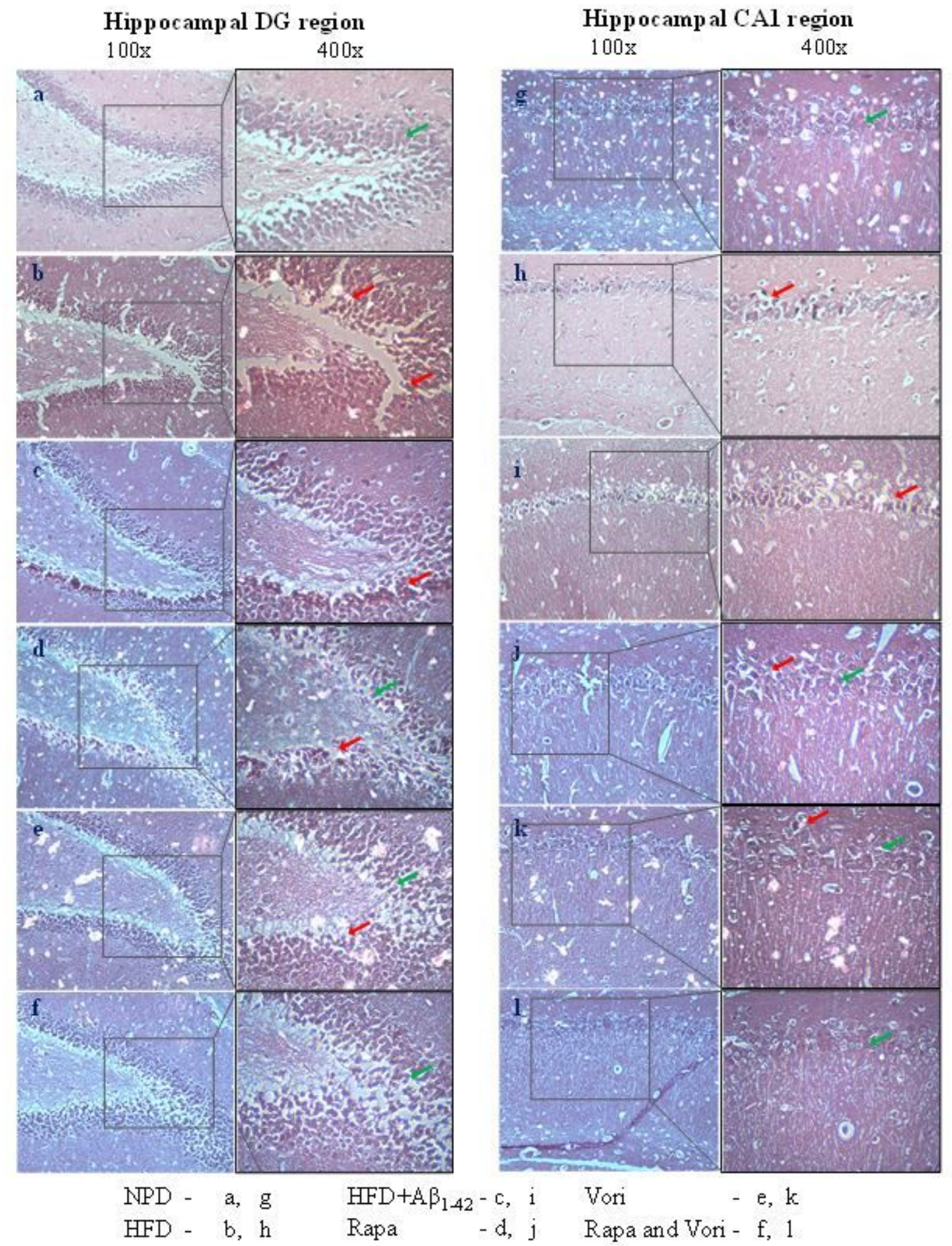

Figure 10

Histochemical images of hippocampal DG region and CA1 region. 

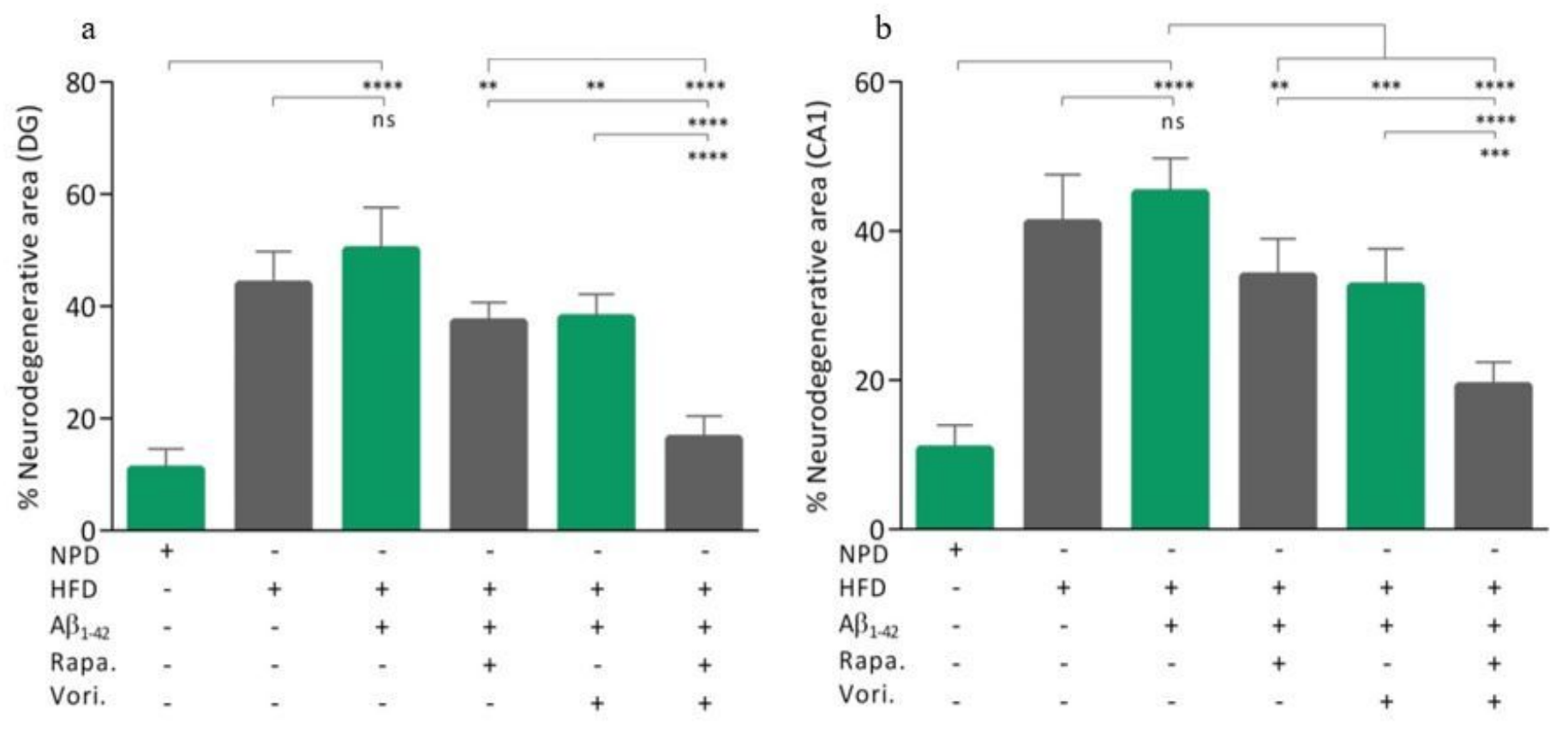

Figure 11

Effect of rapa and vori on hippocampal (a) DG, and (b) CA1 region. Values represent Mean $\pm S D$; ${ }^{* \star} \mathrm{P} \leq 0.01,{ }^{* * *} \mathrm{P} \leq 0.001,{ }^{* \star *} \mathrm{P} \leq 0.0001,(+)=$ with treatment and $(-)=$ without treatment. 